Research Article

\title{
One-Dimensional Consolidation Analysis of Unsaturated Soils under Cyclic Loadings
}

\author{
Pyol Kim (i), ${ }^{1}$ Myongchol Ri ${ }^{1},{ }^{1}$ Yonggun Kim ${ }^{D},{ }^{2}$ Gunhyang Ri, ${ }^{1}$ and Hakbom Myong ${ }^{1}$ \\ ${ }^{1}$ Department of Hydrogeology, Faculty of Geology, Kim II Sung University, Pyongyang 999093, \\ Democratic People's Republic of Korea \\ ${ }^{2}$ Department of Hydrology, Faculty of Global Environmental Science, Kim II Sung University, Pyongyang 999093, \\ Democratic People's Republic of Korea \\ Correspondence should be addressed to Pyol Kim; 18846415254@163.com
}

Received 28 October 2019; Revised 27 January 2020; Accepted 5 February 2020; Published 17 March 2020

Academic Editor: Mario Terzo

Copyright (c) 2020 Pyol Kim et al. This is an open access article distributed under the Creative Commons Attribution License, which permits unrestricted use, distribution, and reproduction in any medium, provided the original work is properly cited.

\begin{abstract}
This paper presents analytical solutions to Fredlund and Hasan's one-dimensional consolidation equations for unsaturated soils subjected to various cyclic loadings. Two new variables are introduced so that the governing equations for excess pore air and water pressures can be transformed to a set of conventional diffusion equations. Based on the general solutions for two introduced variables, the analytical solutions are derived for one-dimensional consolidation of unsaturated soils under trapezoidal, rectangular, triangular, and haversine cyclic loadings. It shows through the degeneration into the existing solutions for unsaturated and saturated soils that the proposed solutions are more general ones for one-dimensional consolidation of soils from unsaturated to saturated states. A comprehensive parametric study is conducted to investigate the effects of different parameters on one-dimensional consolidation of unsaturated soils under various cyclic loadings. The proposed solutions can be effectively utilized in the analysis of consolidation of unsaturated soils subjected to various cyclic loadings.
\end{abstract}

\section{Introduction}

In geotechnical engineering, soils beneath many structures may be subjected to complicated cyclic loadings. These cyclic loadings are induced by different vibration sources, such as filling and discharging in silos, tanks, and reservoirs; traffic loads on highways, railways, or airports; wave action for offshore structures; wind forces in high buildings; pile construction; and machine vibrations. The consolidation characteristics of soils subjected to cyclic loadings are very complex and different from those of soils under simple time-dependent loadings. Thus, consolidation behavior of subsoils under cyclic loadings has drawn considerable attention and has become the focus of academic research.

Over the past few decades, numerous studies have been conducted on consolidation behavior of saturated soils under various cyclic loadings. The existing investigation of consolidation behavior of saturated soils under cyclic loadings can be divided into two groups. One focused on the consolidation based on Terzaghi's linear consolidation theory, while the other was based on the nonlinear consolidation theory. Preceding works on the former included the efforts by Wilson and Elgohary [1], Favaretti and Soranzo [2], Conte and Troncone [3], Razouki and Schanz [4], Razouki et al. [5], and Kim et al. [6]. Wilson and Elgohary [1] presented an analytical solution for one-dimensional consolidation of saturated soil subjected to rectangular cyclic loading, whereas Favaretti and Soranzo [2] and Conte and Troncone [3] derived solutions for different types of cyclic loadings. Razouki and Schanz [4] and Razouki et al. [5] studied one-dimensional consolidation of a clay layer subjected to haversine cyclic loading with and without rest period. Kim et al. [6] investigated 
one-dimensional consolidation behavior of saturated clays under time-dependent loadings including haversine cyclic loading based on the lattice Boltzmann method. The latter mainly included the work by Baligh and Levadoux [7], Xie et al. [8], Geng et al. [9], Cai et al. [10], Conte and Troncone [11], Toufigh and Ouria [12], Cheng et al. [13], $\mathrm{Hu}$ et al. [14], and Kim et al. [15, 16]. Baligh and Levadoux [7] and Toufigh and Ouria [12] analyzed one-dimensional nonlinear consolidation of inelastic clays under rectangular cyclic loading using the superimposing rule. Based on the nonlinear consolidation theory proposed by Davis and Raymond [17], Xie et al. [8], Conte and Troncone [11], Cheng et al. [13], and Kim et al. [15] investigated onedimensional nonlinear consolidation of saturated soil subjected to various cyclic loadings. Hu et al. [14] proposed a numerical method for modelling one-dimensional nonlinear consolidation of multilayer soil under various cyclic loadings based on the differential quadrature method. Geng et al. [9] and Cai et al. [10] developed a semianalytical method for one-dimensional nonlinear consolidation of soil with variable compressibility and permeability under cyclic loadings. More recently, Kim et al. [16] derived analytical solutions for one-dimensional nonlinear consolidation of a saturated clay layer under cyclic loadings with the consideration of variable consolidation coefficient.

Most soils in nature are unsaturated and develop much more complex properties during the consolidation process than saturated soils. In the recent decades, a number of studies on the consolidation theory for unsaturated soil has been conducted, and a great progress has been achieved. Blight [18] derived a consolidation equation for the air phase of dry, rigid, unsaturated soil, whereas Barden [19] presented an analysis of the one-dimensional consolidation of compacted unsaturated clay. By assuming that the water and air phases are continuous, Fredlund and Hasan [20] presented an uncoupled one-dimensional consolidation theory for unsaturated soil, in which two partial differential equations for water and air phases were derived. Meanwhile, some scholars [21-23] proposed coupled models for consolidation in unsaturated soil. Although coupled models are theoretically more rigorous than uncoupled ones, the uncoupled theory proposed by Fredlund and Hasan [20] is now widely accepted because it is generally simple and sufficiently accurate for practical projects $[24,25]$. On the basis of the consolidation theory proposed by Fredlund and Hasan [20], many researchers have investigated consolidation of unsaturated soil under different time-dependent loadings [26-43]. Among them, Feng et al. [30] presented an analytical solution for one-dimensional consolidation of unsaturated soil under sinusoidal cyclic loading. Ho and Fatahi [31] and Wang et al. [32] suggested analytical and semianalytical solutions to Fredlund and Hasan's one-dimensional consolidation of unsaturated soils subjected to different time-dependent loadings including sinusoidal loading. On the contrary, based on the coupled consolidation model of poroelasticity, Lo et al. [44] proposed a closed-form analytical solution for one- dimensional consolidation of unsaturated soil under harmonic cyclic loading.

Despite these advances, it seems that research on consolidation of unsaturated soils subjected to different cyclic loadings is very limited. Most researchers performed investigations on consolidation behavior of unsaturated soils subjected to simple time-dependent loadings, such as constant, ramp, exponential, and a few sine loadings, but little research has been done on consolidation behavior of unsaturated soils under various cyclic loadings.

In this paper, based on the consolidation theory proposed by Fredlund and Hasan [20], analytical solutions are derived for one-dimensional consolidation of unsaturated soils under various cyclic loadings, such as trapezoidal, rectangular, triangular, and haversine cyclic loadings. The proposed solutions are degenerated into the existing solutions for unsaturated soils under constant and ramp loadings and for saturated soils under haversine cyclic loading. Then, a comprehensive parametric study is conducted to investigate the effects of different parameters on one-dimensional consolidation of unsaturated soils under various cyclic loadings.

\section{Governing Equations}

An unsaturated soil layer of thickness $H$ subjected to timedependent loading $q(t)$ is considered as shown in Figure 1. In order to obtain the analytical solution for one-dimensional consolidation of the unsaturated soil layer subjected to time-dependent loading, the main assumptions are summarized as follows:

(1) The flows of air and water phases are continuous and independent

(2) The soil particles and water phase are incompressible

(3) The effects of temperature change, air diffusing through water and air dissolving in the water, and the movement of vapor are ignored

(4) The coefficients of permeability and volume change for both air and water phases remain constant during the consolidation process

(5) The deformation takes place only along the vertical direction

The governing equations for one-dimensional consolidation of unsaturated soils subjected to time-dependent loading are as follows $[19,23]$ :

$$
\begin{aligned}
& \frac{\partial u_{a}}{\partial t}=-C_{a} \frac{\partial u_{w}}{\partial t}+C_{v}^{a} \frac{\partial^{2} u_{a}}{\partial z^{2}}+C_{\sigma}^{a} \frac{\partial q}{\partial t} \\
& \frac{\partial u_{w}}{\partial t}=-C_{w} \frac{\partial u_{a}}{\partial t}+C_{v}^{w} \frac{\partial^{2} u_{w}}{\partial z^{2}}+C_{\sigma}^{w} \frac{\partial q}{\partial t}
\end{aligned}
$$

where $u_{\mathrm{a}}$ and $u_{\mathrm{w}}$ are the excess pore air and pore water pressures, respectively. The consolidation parameters can be expressed as follows: 


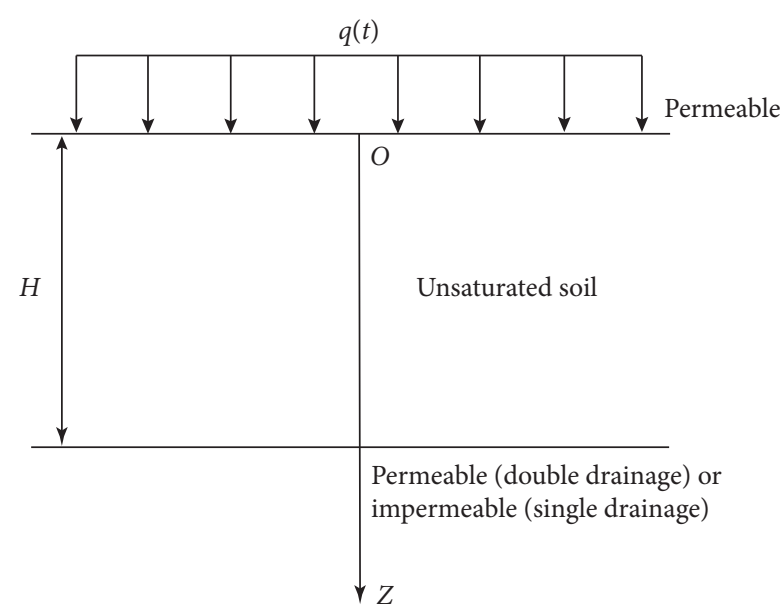

Figure 1: An unsaturated soil layer subjected to time-dependent loading.

$$
\begin{aligned}
& C_{a}=\frac{m_{2}^{a}}{m_{1}^{a}-m_{2}^{a}-n_{0}\left(1-S_{r 0}\right) / \widehat{u}_{a}}, \\
& C_{v}^{a}=\frac{k_{a} \mathrm{RT}_{\mathrm{abs}}}{g \widehat{u}_{a} M_{a}\left[m_{1}^{a}-m_{2}^{a}-n_{0}\left(1-S_{r 0}\right) / \widehat{u}_{a}\right]}, \\
& C_{\sigma}^{a}=\frac{m_{1}^{a}}{m_{1}^{a}-m_{2}^{a}-n_{0}\left(1-S_{r 0}\right) / \widehat{u}_{a}}, \\
& C_{w}=\frac{1-m_{2}^{w} / m_{1}^{w}}{m_{2}^{w} / m_{1}^{w}} \\
& C_{v}^{w}=\frac{k_{w}}{\gamma_{w} m_{2}^{w}} \\
& C_{\sigma}^{w}=\frac{m_{1}^{w}}{m_{2}^{w}}
\end{aligned}
$$

where $m_{1}^{a}$ and $m_{1}^{w}$ are the coefficients of air and water volume change with respect to a change in the net normal stress $\left(\sigma-u_{a}\right)$, respectively; $m_{2}^{a}$ and $m_{2}^{w}$ are the coefficients of air and water volume change with respect to a change in the matric suction $\left(u_{a}-u_{w}\right)$, respectively; $k_{a}$ and $k_{w}$ are the coefficients of permeability for air and water phases, respectively; $g$ is the gravitational acceleration; $\widehat{u}_{a}$ is the absolute pore air pressure, $\widehat{u}_{a}=u_{a}+\widehat{u}_{\text {atm }}$, in which $\widehat{u}_{\text {atm }}$ is the atmospheric pressure, $101 \mathrm{kPa}$; when the pore air pressure $u_{a}$ is small or rapidly dissipates during consolidation, $\widehat{u}_{a}$ can be considered constant, and therefore, in this study, $\widehat{u}_{a}=\widehat{u}_{\mathrm{atm}}$; $M_{a}$ is the molecular mass of air, $0.029 \mathrm{~kg} / \mathrm{mol}$; $R$ is the universal gas constant, $8.314 \mathrm{~J} / \mathrm{mol} / \mathrm{K} ; T_{\text {abs }}$ is the absolute temperature, $(20+273.16) \mathrm{K} ; n_{0}$ is the initial porosity; $S_{r 0}$ is the initial degree of saturation; and $\gamma_{w}$ is the unit weight of water.

The initial excess pore air and pore water pressures can be expressed as follows:

$$
\begin{aligned}
& u_{a}(z, 0)=u_{a}^{0}, \\
& u_{w}(z, 0)=u_{w}^{0},
\end{aligned}
$$

where $u_{a}^{0}$ and $u_{w}^{0}$ are the initial excess pore air and pore water pressures, respectively.

The boundary conditions for the excess pore air and pore water pressures can be given by the following equations:

$$
\begin{aligned}
u_{a}(0, t) & =0, \\
u_{w}(0, t) & =0, \\
\frac{\partial u_{a}(H, t)}{\partial z} & =0, \\
\frac{\partial u_{w}(H, t)}{\partial z} & =0 \text { (for single drainage condition), } \\
u_{a}(H, t) & =0, \\
u_{w}(H, t) & =0 \text { (for double drainage condition). }
\end{aligned}
$$

Equations (1) and (2) can be presented in nondimensional form by using nondimensional parameters:

$$
\begin{gathered}
\frac{\partial \bar{u}_{a}}{\partial T}=A_{a} \frac{\partial^{2} \bar{u}_{a}}{\partial \bar{z}^{2}}+A_{w} \frac{\partial^{2} \bar{u}_{w}}{\partial \bar{z}^{2}}+A_{\sigma} \frac{\partial \bar{q}}{\partial T}, \\
\frac{\partial \bar{u}_{w}}{\partial T}=W_{a} \frac{\partial^{2} \bar{u}_{a}}{\partial \bar{z}^{2}}+W_{w} \frac{\partial^{2} \bar{u}_{w}}{\partial \bar{z}^{2}}+W_{\sigma} \frac{\partial \bar{q}}{\partial T},
\end{gathered}
$$

where $\quad \bar{u}_{a}=u_{a} / q_{u}, \quad \bar{u}_{w}=u_{w} / q_{u}, \quad \bar{q}=q / q_{u}, \quad \bar{z}=z / H$, $q_{u}=$ ultimate value of loading $q, T=\left(k_{w} / \gamma_{w} m_{1}^{s}\right)\left(t / H^{2}\right)$, $m_{1}^{s}=$ coefficient of volume change with respect to a change in net normal stress $\left(\sigma-u_{a}\right), m_{1}^{s}=m_{1}^{a}+m_{1}^{w}$,

$$
\begin{aligned}
A_{a} & =\frac{C_{v}^{a}}{1-C_{w} C_{a}} \cdot \frac{\gamma_{w} m_{1}^{s}}{k_{w}}, \\
A_{w} & =\frac{-C_{a} C_{v}^{w}}{1-C_{w} C_{a}} \cdot \frac{\gamma_{w} m_{1}^{s}}{k_{w}}, \\
A_{\sigma} & =\frac{C_{\sigma}^{a}-C_{a} C_{\sigma}^{w}}{1-C_{w} C_{a}}, \\
W_{a} & =\frac{-C_{w} C_{v}^{a}}{1-C_{w} C_{a}} \cdot \frac{\gamma_{w} m_{1}^{s}}{k_{w}}, \\
W_{w} & =\frac{C_{v}^{w}}{1-C_{w} C_{a}} \cdot \frac{\gamma_{w} m_{1}^{s}}{k_{w}}, \\
W_{\sigma} & =\frac{C_{\sigma}^{w}-C_{w} C_{\sigma}^{a}}{1-C_{w} C_{a}} .
\end{aligned}
$$

The dimensionless initial and boundary conditions can be expressed as follows: 


$$
\begin{aligned}
\bar{u}_{a}(\bar{z}, 0) & =\bar{u}_{a}^{0}, \\
\bar{u}_{w}(\bar{z}, 0) & =\bar{u}_{w}^{0}, \\
\bar{u}_{a}(0, T) & =0 \\
\bar{u}_{w}(0, T) & =0 \\
\frac{\partial \bar{u}_{a}(1, T)}{\partial \bar{z}} & =0 \\
\frac{\partial \bar{u}_{w}(1, T)}{\partial \bar{z}} & =0 \text { (for single drainage condition), } \\
\bar{u}_{a}(1, T) & =0, \\
\bar{u}_{w}(1, T) & =0 \text { (for double drainage condition), }
\end{aligned}
$$

where $\bar{u}_{a}^{0}=u_{a}^{0} / q_{u}$ and $\bar{u}_{w}^{0}=u_{w}^{0} / q_{u}$.

\section{Derivation of Analytical Solutions under Cyclic Loadings}

According to the simple analytical solutions presented by Zhou et al. [29], (8) and (9) can be transformed to a set of conventional diffusion equations by introducing two new variables $\phi_{1}$ and $\phi_{2}$ :

$$
\frac{\partial \phi_{i}}{\partial T}=\xi_{i}\left(\frac{\partial^{2} \phi_{i}}{\partial \bar{z}^{2}}\right)+\eta_{i}\left(\frac{\partial \bar{q}}{\partial T}\right), \quad i=1,2,
$$

where

$$
\begin{aligned}
\phi_{1} & =\bar{u}_{a}+\alpha_{21} \bar{u}_{w}, \\
\phi_{2} & =\alpha_{12} \bar{u}_{a}+\bar{u}_{w}, \\
\xi_{1,2} & =\frac{1}{2\left[A_{a}+W_{w} \pm \sqrt{\left(A_{a}-W_{w}\right)^{2}+4 A_{w} W_{a}}\right]}, \\
\eta_{1} & =A_{\sigma}+\alpha_{21} W_{\sigma}, \\
\eta_{2} & =\alpha_{12} A_{\sigma}+W_{\sigma}, \\
\alpha_{12} & =\frac{W_{a}}{\xi_{2}-A_{a}}, \\
\alpha_{21} & =\frac{A_{w}}{\xi_{1}-W_{w}} .
\end{aligned}
$$

The corresponding initial and boundary conditions for excess pore air and pore water pressures can be transformed as follows:

$$
\begin{gathered}
\phi_{i}(\bar{z}, 0)=\phi_{i}^{0}, \quad i=1,2, \\
\phi_{i}(0, T)=0, \quad i=1,2, \\
\frac{\partial \phi_{i}(1, T)}{\partial \bar{z}}=0, \quad i=1,2 \text { (for single drainage condition), } \\
\phi_{i}(1, T)=0, \quad i=1,2 \text { (for double drainage condition), }
\end{gathered}
$$

where $\phi_{1}^{0}=\bar{u}_{a}^{0}+\alpha_{21} \bar{u}_{w}^{0}$ and $\phi_{2}^{0}=\alpha_{12} \bar{u}_{a}^{0}+\bar{u}_{w}^{0}$.

For the single drainage condition, the general solutions of (10) subjected to the solution conditions of (12)-(14) can be obtained as follows:

$$
\phi_{i}=\sum_{m=1}^{\infty} \frac{2}{M} \sin (M \bar{z}) e^{-\beta_{m} T} T_{m}(T),
$$

where $\quad M=(2 m-1) \pi / 2, m=1,2,3, \ldots, \quad \beta_{m}=M^{2} \xi_{\text {i }}$, $T_{m}(T)=\int_{0}^{T} e^{\beta_{m} \tau} R(\tau) \mathrm{d} \tau$, and $R(T)=\eta_{i}(\partial \bar{q} / \partial T)$, in which $i=1,2$.

The solutions for the double drainage condition can be easily obtained by replacing $\bar{z}$ in (16) with $2 \bar{z}$ considering the drainage height (i.e., $H / 2$ ).

The complete solutions of $\phi_{i}$ for various cyclic loadings can be calculated by substituting the different loading functions into (16).

On the basis of the definition of the average degree of consolidation, the degree of consolidation, $U_{i}$, with respect to $\phi_{i}$ for different cyclic loadings can be expressed as follows:

$$
U_{i}=\eta_{i} \bar{q}-\int_{0}^{1} \phi_{i} \mathrm{~d} \bar{z}, \quad i=1,2 .
$$

The detailed mathematical process of obtaining the degree of consolidation, $U_{i}$, can be found in Appendix.

3.1. Trapezoidal Cyclic Loading. Trapezoidal cyclic loading shown in Figure 2(a) can be expressed as follows:

$$
q(t)= \begin{cases}\frac{q_{u}}{\alpha t_{0}}\left[t-(N-1) \beta t_{0}\right], & (N-1) \beta t_{0} \leq t \leq[(N-1) \beta+\alpha] t_{0}, \\ q_{u}, & {[(N-1) \beta+\alpha] t_{0} \leq t \leq[(N-1) \beta+(1-\alpha)] t_{0},} \\ -\frac{q_{u}}{\alpha t_{0}}\left[t-(N-1) \beta t_{0}-t_{0}\right], & {[(N-1) \beta+(1-\alpha)] t_{0} \leq t \leq[(N-1) \beta+1] t_{0},} \\ 0, & {[(N-1) \beta+1] t_{0} \leq t \leq N \beta t_{0},}\end{cases}
$$




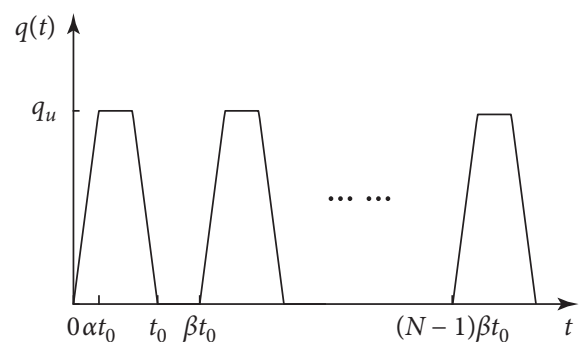

(a)

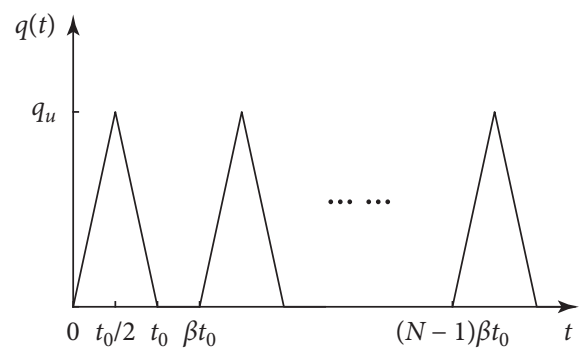

(c)

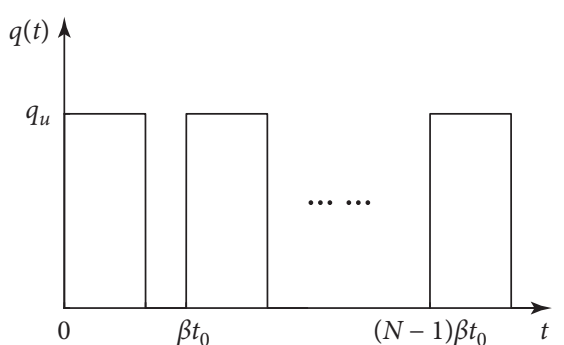

(b)

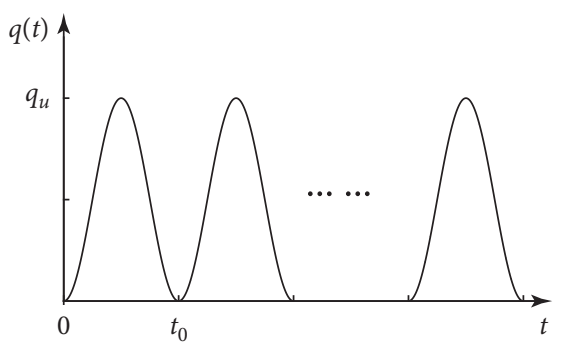

(d)

FIGURE 2: Various cyclic loadings: (a) trapezoidal cyclic loading; (b) rectangular cyclic loading; (c) triangular cyclic loading; (d) haversine cyclic loading.

where $t_{0}$ is the period of one loading cycle; $\alpha$ and $\beta$ are the loading parameters corresponding to the rate of loading increment or decrement and the rest period of loading, respectively; and $N$ is the cycle number.
Transforming (18) into nondimensional form and substituting into (16), the complete solutions of (10) can be obtained as follows:

$$
\phi_{i}= \begin{cases}\sum_{m=1}^{\infty} \frac{2 C_{1 i}}{M} \sin (M \bar{z}) e^{-M^{2} \xi_{i} T}, & (N-1) \beta t_{0} \leq t \leq[(N-1) \beta+\alpha] t_{0} \\ \sum_{m=1}^{\infty} \frac{2 C_{2 i}}{M} \sin (M \bar{z}) e^{-M^{2} \xi_{i} T}, & {[(N-1) \beta+\alpha] t_{0} \leq t \leq[(N-1) \beta+(1-\alpha)] t_{0}} \\ \sum_{m=1}^{\infty} \frac{2 C_{3 i}}{M} \sin (M \bar{z}) e^{-M^{2} \xi_{i} T} & {[(N-1) \beta+(1-\alpha)] t_{0} \leq t \leq[(N-1) \beta+1] t_{0}} \\ \sum_{m=1}^{\infty} \frac{2 C_{4 i}}{M} \sin (M \bar{z}) e^{-M^{2} \xi_{i} T}, & {[(N-1) \beta+1] t_{0} \leq t \leq N \beta t_{0}}\end{cases}
$$

where

$$
\begin{aligned}
C_{1 i} & =D_{i}(N-1)+D_{1 i}, \\
C_{2 i} & =D_{i}(N-1)+D_{2 i}, \\
C_{3 i} & =D_{i}(N-1)+D_{2 i}+D_{3 i}, \\
C_{4 i} & =D_{i}(N), \\
D_{i}(n) & =\sum_{N=1}^{n}\left(D_{2 i}+D_{4 i}\right), \\
D_{1 i} & =\frac{\eta_{i}}{M^{2} \xi_{i} T_{c}}\left(e^{M^{2} \xi_{i} T}-e^{M^{2} \xi_{i} T_{b}}\right),
\end{aligned}
$$

$$
\begin{aligned}
D_{2 i} & =\frac{\eta_{i}}{M^{2} \xi_{i} T_{c}} e^{M^{2} \xi_{i} T_{b}}\left(e^{M^{2} \xi_{i} T_{c}}-1\right), \\
D_{3 i} & =-\frac{\eta_{i}}{M^{2} \xi_{i} T_{c}}\left[e^{M^{2} \xi_{i} T}-e^{M^{2} \xi_{i}\left(T_{f}-T_{c}\right)}\right], \\
D_{4 i} & =-\frac{\eta_{i}}{M^{2} \xi_{i} T_{c}} e^{M^{2} \xi_{i} T_{f}}\left(1-e^{-M^{2} \xi_{i} T_{c}}\right), \\
T_{c} & =\frac{k_{w}}{\gamma_{w} m_{1}^{s}} \cdot \frac{\alpha t_{0}}{H^{2}}, \\
T_{b} & =\frac{k_{w}}{\gamma_{w} m_{1}^{s}} \cdot \frac{(N-1) \beta t_{0}}{H^{2}}, \\
T_{f} & =\frac{k_{w}}{\gamma_{w} m_{1}^{s}} \cdot \frac{[(N-1) \beta+1] t_{0}}{H^{2}}, \\
i & =1,2 .
\end{aligned}
$$


Substituting (19) into (17), the solutions of $U_{i}$ for trapezoidal cyclic loading can be given as follows:

$$
U_{i}= \begin{cases}\frac{\eta_{i}}{T_{c}}\left(T-T_{b}\right)-\sum_{m=1}^{\infty} \frac{2 C_{1 i}}{M^{2}} e^{-M^{2} \xi_{i} T}, & (N-1) \beta t_{0} \leq t \leq[(N-1) \beta+\alpha] t_{0}, \\ \eta_{i}-\sum_{m=1}^{\infty} \frac{2 C_{2 i}}{M^{2}} e^{-M^{2} \xi_{i} T}, & {[(N-1) \beta+\alpha] t_{0} \leq t \leq[(N-1) \beta+(1-\alpha)] t_{0},} \\ \frac{\eta_{i}}{T_{c}}\left(T_{f}-T\right)-\sum_{m=1}^{\infty} \frac{2 C_{3 i}}{M^{2}} e^{-M^{2} \xi_{i} T}, & {[(N-1) \beta+(1-\alpha)] t_{0} \leq t \leq[(N-1) \beta+1] t_{0},} \\ -\sum_{m=1}^{\infty} \frac{2 C_{4 i}}{M^{2}} e^{-M^{2} \xi_{i} T}, & {[(N-1) \beta+1] t_{0} \leq t \leq N \beta t_{0},}\end{cases}
$$

where $i=1,2$.

3.2. Rectangular and Triangular Cyclic Loadings. Rectangular and triangular cyclic loadings can be degenerated from trapezoidal cyclic loading. When $\alpha \longrightarrow 0$, trapezoidal cyclic loading reduces into rectangular cyclic loading (Figure 2(b)). In addition, trapezoidal cyclic loading reduces to triangular cyclic loading (Figure 2(c)) when $\alpha=0.5$. Therefore, the solutions of $\phi_{i}$ and $U_{i}$ for rectangular and triangular cyclic loadings can be given by substituting $\alpha=0$ and $\alpha=0.5$ into (19) and (21), respectively.

3.3. Haversine Cyclic Loading. Haversine cyclic loading shown in Figure 2(d) can be expressed as follows:

$$
q(t)=q_{u} \sin ^{2}\left(\frac{\pi t}{t_{0}}\right) .
$$

Transforming (22) into nondimensional form and substituting into (16), the complete solutions of (10) can be obtained as follows:

$$
\phi_{i}=\sum_{m=1}^{\infty} \frac{2 C_{i}}{M} \sin (M \bar{z}) e^{-M^{2} \xi_{i} T}, \quad i=1,2,
$$

where

$$
\begin{aligned}
C_{i}= & \frac{\eta_{i} \pi}{M^{4} \xi_{i}^{2} T_{0}^{2}+4 \pi^{2}}\left\{M^{2} \xi_{i} T_{0} \sin \left(\frac{2 \pi T}{T_{0}}\right) e^{M^{2} \xi_{i} T}\right. \\
& \left.-2 \pi\left[\cos \left(\frac{2 \pi T}{T_{0}}\right) e^{M^{2} \xi_{i} T}-1\right]\right\}, \quad i=1,2, \\
T_{0}= & \frac{k_{w}}{\gamma_{w} m_{1}^{s}} \frac{t_{0}}{H^{2}} .
\end{aligned}
$$

Substituting (23) into (17), the solutions of $U_{i}$ for haversine cyclic loading can be given as follows:

$$
U_{i}=\eta_{i} \sin ^{2}\left(\frac{\pi T}{T_{0}}\right)-\sum_{m=1}^{\infty} \frac{2 C_{i}}{M^{2}} e^{-M^{2} \xi_{i} T}, \quad i=1,2 .
$$

3.4. Excess Pore Pressures and Average Degree of Consolidation. Based on the solutions of $\phi_{i}$, the normalized excess pore air and pore water pressures can be given by following relations:

$$
\begin{aligned}
& \bar{u}_{a}=\frac{\alpha_{21} \phi_{2}-\phi_{1}}{\alpha_{12} \alpha_{21}-1}, \\
& \bar{u}_{w}=\frac{\alpha_{12} \phi_{1}-\phi_{2}}{\alpha_{12} \alpha_{21}-1} .
\end{aligned}
$$

Based on the solutions of $U_{i}$ for different cyclic loadings, the average degrees of consolidation for both air and water phases can be expressed as follows:

$$
\begin{aligned}
& U_{a}=\frac{\alpha_{21} U_{2}-U_{1}}{\left(\alpha_{12} \alpha_{21}-1\right) A_{\sigma}} \cdot 100(\%), \\
& U_{w}=\frac{\alpha_{12} U_{1}-U_{2}}{\left(\alpha_{12} \alpha_{21}-1\right) W_{\sigma}} \cdot 100(\%),
\end{aligned}
$$

where $U_{a}$ and $U_{w}$ are the average degrees of consolidation for air phase and water phase, respectively.

\section{Degeneration of the Proposed Solution to Special Cases}

The proposed solutions can be degenerated into the existing solutions for one-dimensional consolidation of both unsaturated and saturated soils subjected to different timedependent loadings.

4.1. Constant Loading. When $\alpha=0, \beta=1$, and $N=1$, trapezoidal cyclic loading reduces to constant loading (Figure 3(a)) expressed by $q(t)=q_{u}$. Then, the solutions of $\phi_{i}$ and $U_{i}$ can be given by

$$
\begin{aligned}
& \phi_{i}=\sum_{m=1}^{\infty} \frac{2 \phi_{i}^{0}}{M} \sin (M \bar{z}) e^{-M^{2} \xi_{i} T}, \quad i=1,2, \\
& U_{i}=\phi_{i}^{0}-\sum_{m=1}^{\infty} \frac{2 \phi_{i}^{0}}{M^{2}} e^{-M^{2} \xi_{i} T}, \quad i=1,2 .
\end{aligned}
$$




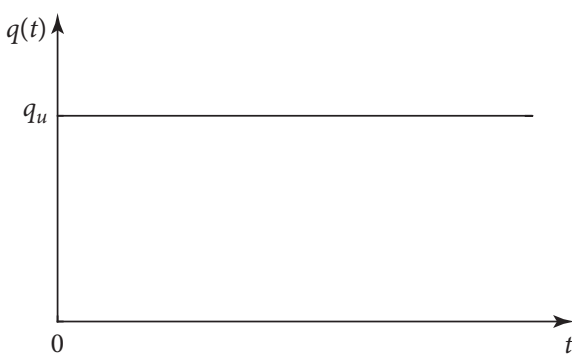

(a)

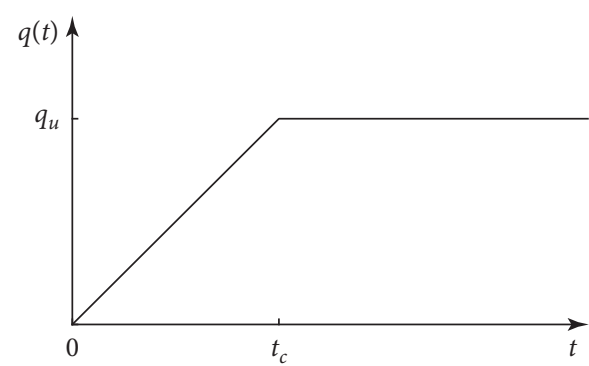

(b)

Figure 3: Constant loading (a) and ramp loading (b).

Equations (29) and (30) are the solutions of $\phi_{i}$ and $U_{i}$ for one-dimensional consolidation of unsaturated soil under constant loading and constant initial condition proposed by Zhou et al. [29].

It can be seen from Figure 4 that the degenerate solutions from this paper are consistent with the existing solutions and the proposed solutions are accurate.

4.2. Ramp Loading. When $N=1$ and $t_{0}$ tends to infinity, trapezoidal cyclic loading reduces to ramp loading (Figure 3(b)) given by

$$
q(t)= \begin{cases}\frac{t}{t_{c}} q_{u}, & t \leq t_{c}, \\ q_{u}, & t \geq t_{c},\end{cases}
$$

where $t_{c}=\alpha t_{0}$.

The solutions of $\phi_{i}$ and $U_{i}$ can be obtained by

$$
\begin{aligned}
& \phi_{i}= \begin{cases}\sum_{m=1}^{\infty} \frac{2 \eta_{i}}{M^{3} \xi_{i} T_{c}} \sin (M \bar{z})\left(1-e^{-M^{2} \xi_{i} T}\right), & t \leq t_{c}, \\
\sum_{m=1}^{\infty} \frac{2 \eta_{i}}{M^{3} \xi_{i} T_{c}} \sin (M \bar{z}) e^{-M^{2} \xi_{i} T}\left(e^{M^{2} \xi_{i} T_{c}}-1\right), & t \geq t_{c},\end{cases} \\
& U_{i}= \begin{cases}\frac{\eta_{i} T}{T_{c}}-\sum_{m=1}^{\infty} \frac{2 \eta_{i}}{M^{4} \xi_{i} T_{c}}\left(1-e^{-M^{2} \xi_{i} T}\right), & t \leq t_{c}, \\
\eta_{i}-\sum_{m=1}^{\infty} \frac{2 \eta_{i}}{M^{4} \xi_{i} T_{c}} e^{-M^{2} \xi_{i} T}\left(e^{M^{2} \xi_{i} T_{c}}-1\right), & t \geq t_{c}\end{cases}
\end{aligned}
$$

where $i=1,2$ and $T_{c}=\left(k_{w} / \gamma_{w} m_{1}^{s}\right) \cdot\left(t_{c} / H^{2}\right)$.

Equations (32) and (33) are the solutions of $\phi_{i}$ and $U_{i}$ for one-dimensional consolidation of unsaturated soil subjected to ramp loading proposed by Zhou et al. [29].

Figure 5 shows the comparison between the degenerate solutions and the existing solutions by Zhou et al. [29] for ramp loading. It can be found that the degenerate solutions from this paper show good agreement with the existing results, which proves that the proposed solutions are more general ones for one-dimensional consolidation of unsaturated soil under time-dependent loading.

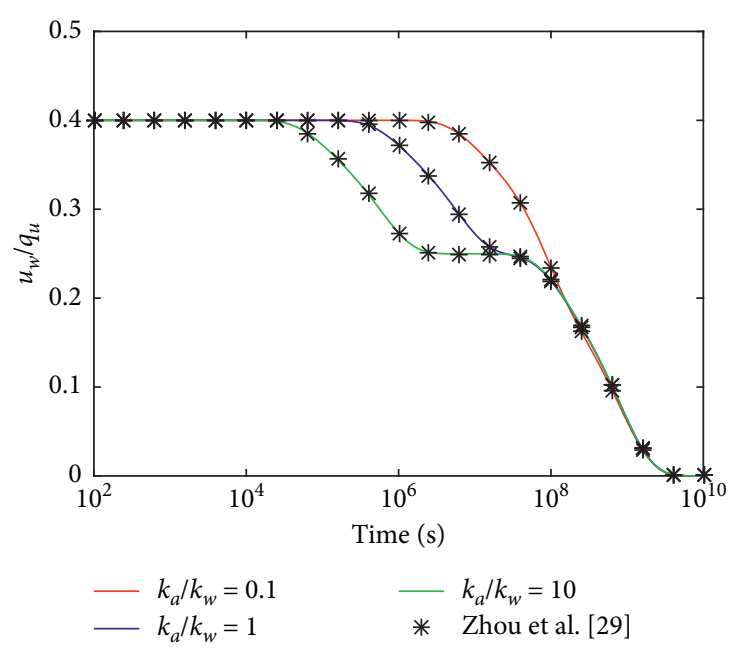

(a)

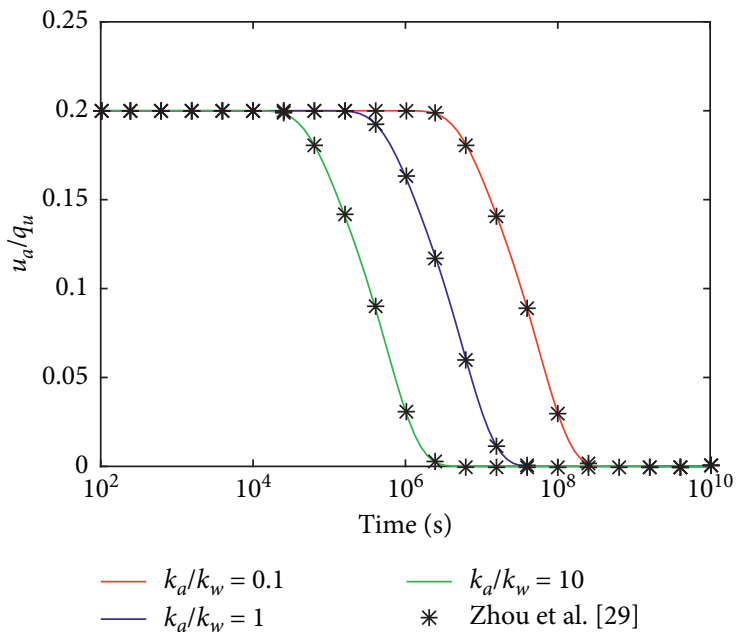

(b)

Figure 4: Comparison between the degenerate solution and the existing solution for constant loading.

4.3. Degeneration to Saturated Condition for Haversine Cyclic Loading. The consolidation coefficients for unsaturated soil can be reduced to those for saturated soil: the coefficients of water volume change $\left(m_{1}^{w}\right.$ and $\left.m_{2}^{w}\right)$ are equal to the coefficient of volume change $\left(m_{v}\right)$; the coefficients of air volume change $\left(m_{1}^{a}\right.$ and $m_{2}^{a}$ ) are zero; air pressure may be assumed to be equal to 


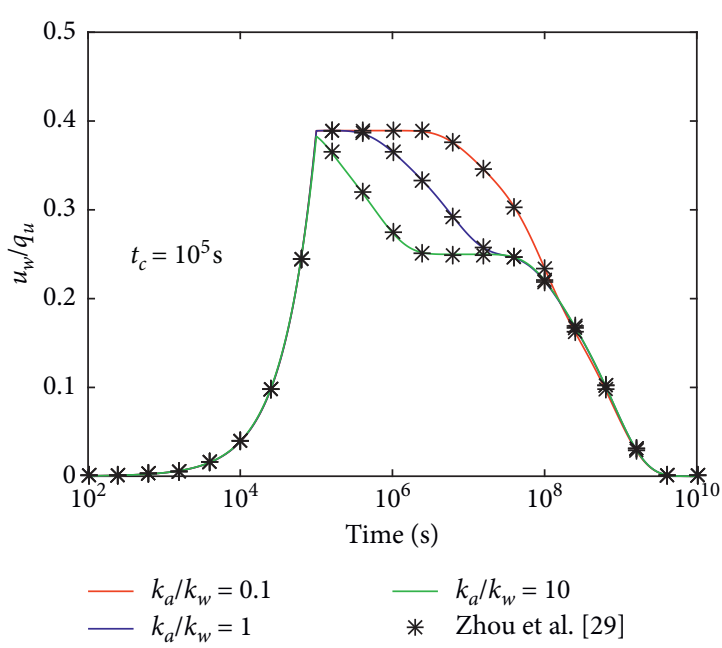

(a)

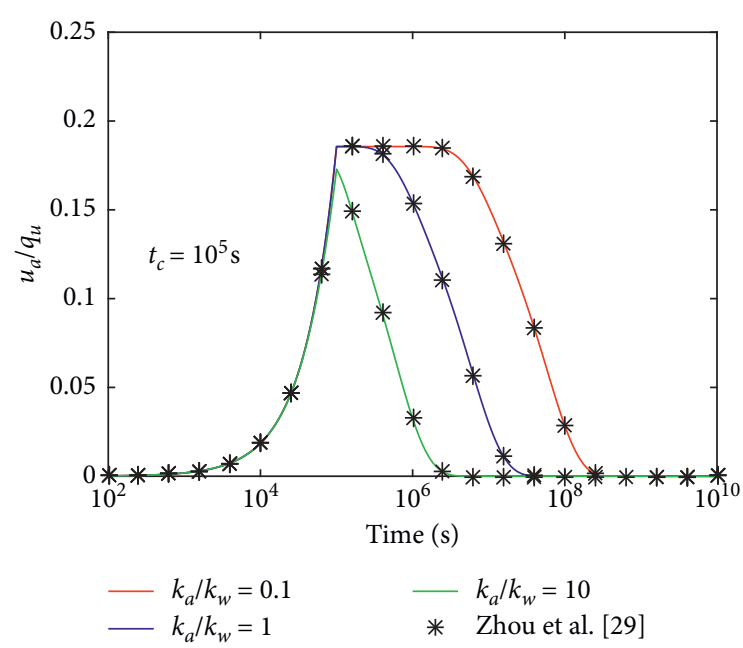

(b)

FIgURE 5: Comparison between the degenerate solution and the existing solution for ramp loading.

water pressure, that is, $u_{a}-u_{w}=0 ; C_{w}=0, C_{v}^{w}=C_{v}=$ $k_{w} / \gamma_{w} m_{v}, C_{\sigma}^{w}=1, C_{a}=0, C_{v}^{a}=0$, and $C_{\sigma}^{a}=0$. Then, the corresponding parameters in (8) and (9) become $A_{a}=0$, $A_{w}=0, A_{\sigma}=0, W_{a}=0, W_{w}=1$, and $W_{\sigma}=1$. In addition, $\xi_{1}=0, \xi_{2}=1, \alpha_{12}=0, \alpha_{21}=0, \eta_{1}=0$, and $\eta_{2}=1$. It follows from (26) and (27) that $\bar{u}_{w}=\phi_{2}$. The solution for the excess pore water pressure of saturated soil with single drainage condition under haversine cyclic loading can be obtained as follows:

$$
\bar{u}_{w}=\phi_{2}=\sum_{m=1}^{\infty} \frac{2 C_{2}}{M} \sin (M \bar{z}) e^{-M^{2} T},
$$

where

$$
\begin{aligned}
C_{2}= & \frac{\pi}{M^{4} T_{0}^{2}+4 \pi^{2}}\left\{M^{2} T_{0} \sin \left(\frac{2 \pi T}{T_{0}}\right) e^{M^{2} T}\right. \\
& \left.-2 \pi\left[\cos \left(\frac{2 \pi T}{T_{0}}\right) e^{M^{2} T}-1\right]\right\}, \\
T_{0}= & \frac{k_{w}}{\gamma_{w} m_{1}^{s}} \frac{t_{0}}{H^{2}} .
\end{aligned}
$$

Equation (34) is the solution for one-dimensional consolidation of saturated soil subjected to haversine cyclic loading proposed by Razouki et al. [5].

As observed in Figure 6, identical results are obtained from both analytical solutions, suggesting that the proposed solutions are reliable as well as more general for one-dimensional consolidation of a soil from unsaturated to saturated states.

\section{Parametric Study}

In this section, a comprehensive parametric study is conducted to investigate the effects of the coefficients ratio of permeability for air and water phases and the other loading parameters on consolidation behavior of unsaturated soils with single drainage condition under various cyclic loadings. The material properties adopted in this study are as follows:

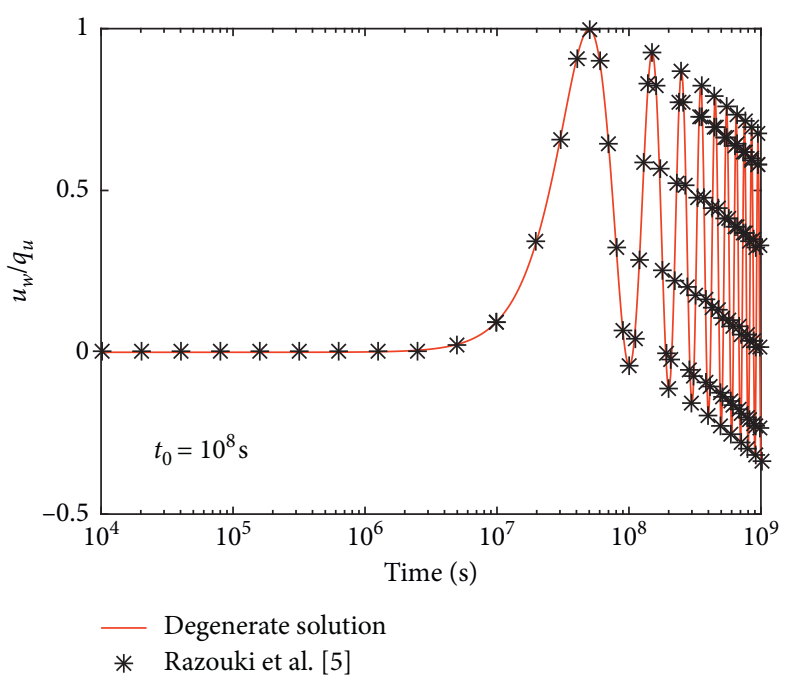

FIgure 6: Comparison between the degenerate solution and the existing solution for haversine cyclic loading.

$$
\begin{aligned}
n_{0} & =0.50, \\
S_{r 0} & =0.80, \\
k_{w} & =10^{-10} \mathrm{~m} / \mathrm{s}, \\
H & =10 \mathrm{~m}, \\
q_{u} & =100 \mathrm{kPa}, \\
m_{1}^{s} & =-2.5 \times 10^{-4} \mathrm{kPa}^{-1}, \\
m_{2}^{s} & =0.4 m_{1}^{s}, \\
m_{1}^{w} & =0.2 m_{1}^{s}, \\
m_{2}^{w} & =4 m_{1}^{w} .
\end{aligned}
$$

The initial excess pore air and pore water pressures are assumed to be zero (i.e., $u_{a}^{0}=0$ and $u_{w}^{0}=0$ ) because of $q(0)=0$ for cyclic loadings except for rectangular cyclic loading, while $u_{a}^{0}=20 \mathrm{kPa}$ and $u_{w}^{0}=40 \mathrm{kPa}$ (constant with depth) for rectangular cyclic loading and constant loading.

5.1. Effects of $k_{a} / k_{w}$. Figures 7 and 8 represent the variation in the average degrees of consolidation for both water and air 

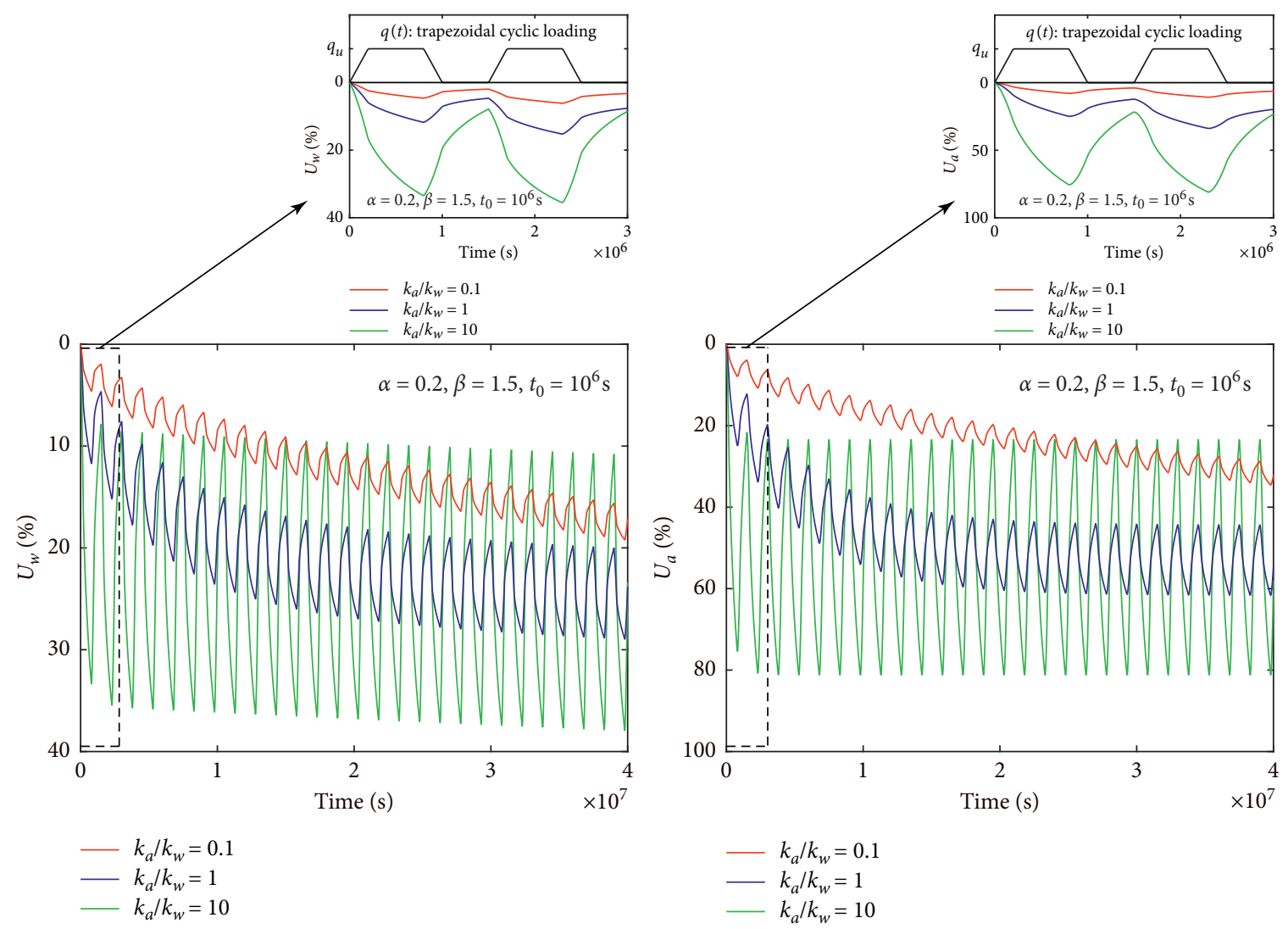

(a)
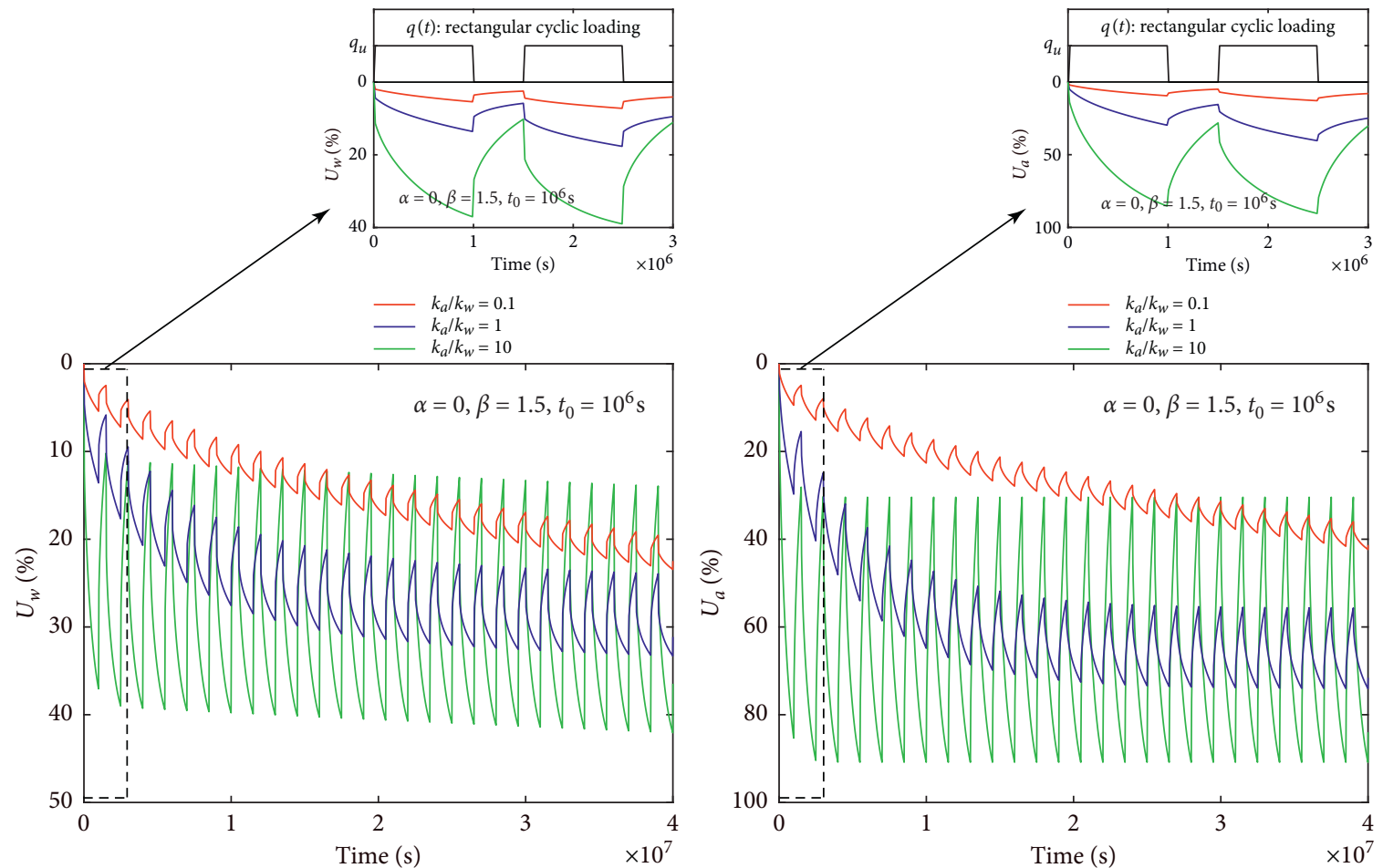

$$
\begin{aligned}
-k_{a} / k_{w} & =0.1 \\
-k_{a} / k_{w} & =1 \\
k_{a} / k_{w} & =10
\end{aligned}
$$$$
\begin{aligned}
-k_{a} / k_{w} & =0.1 \\
-k_{a} / k_{w} & =1 \\
k_{a} / k_{w} & =10
\end{aligned}
$$

(b)

FIGURE 7: The effects of $k_{a} / k_{w}$ on consolidation of unsaturated soils under trapezoidal cyclic loading (a) and rectangular cyclic loading (b). 

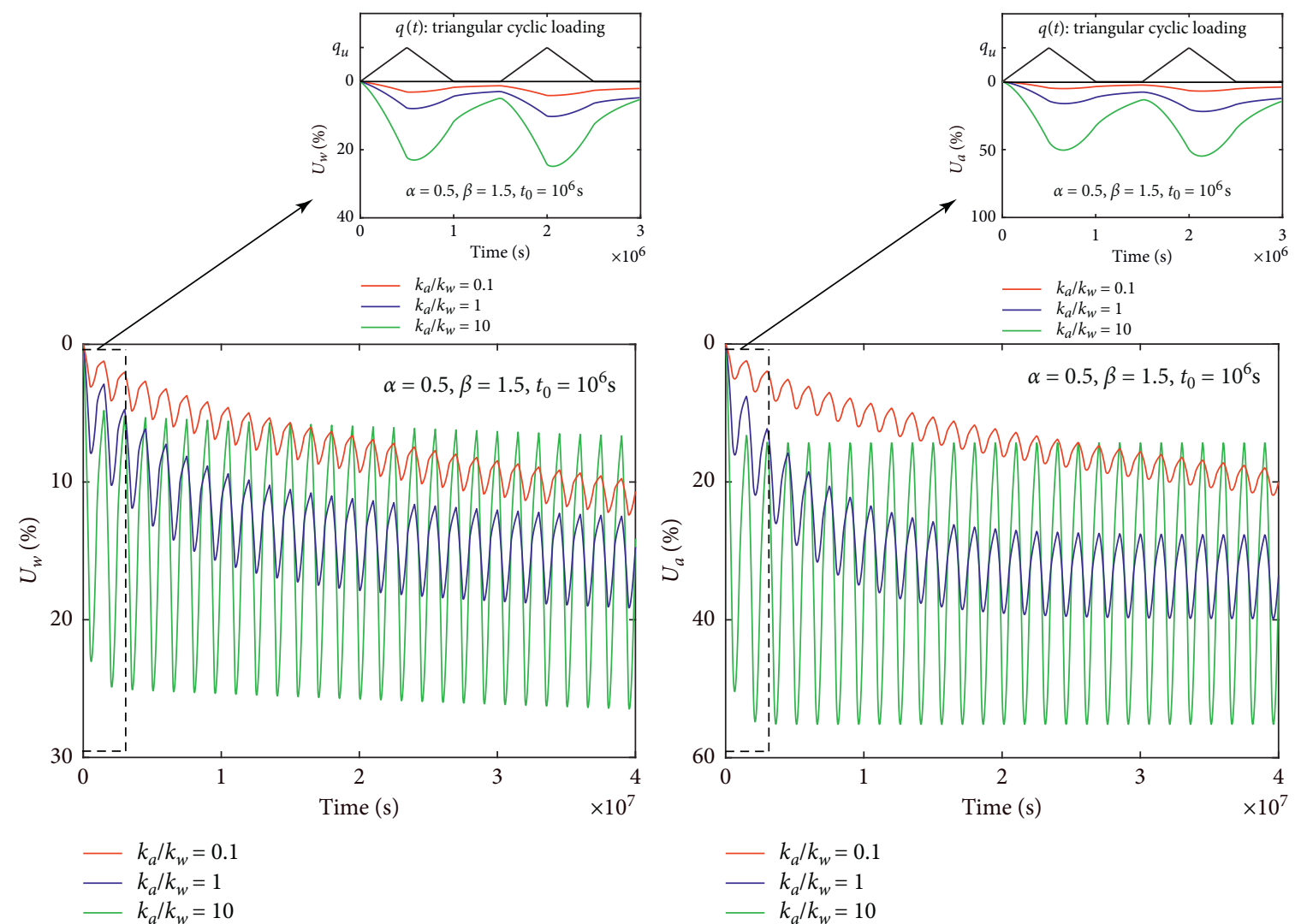

(a)
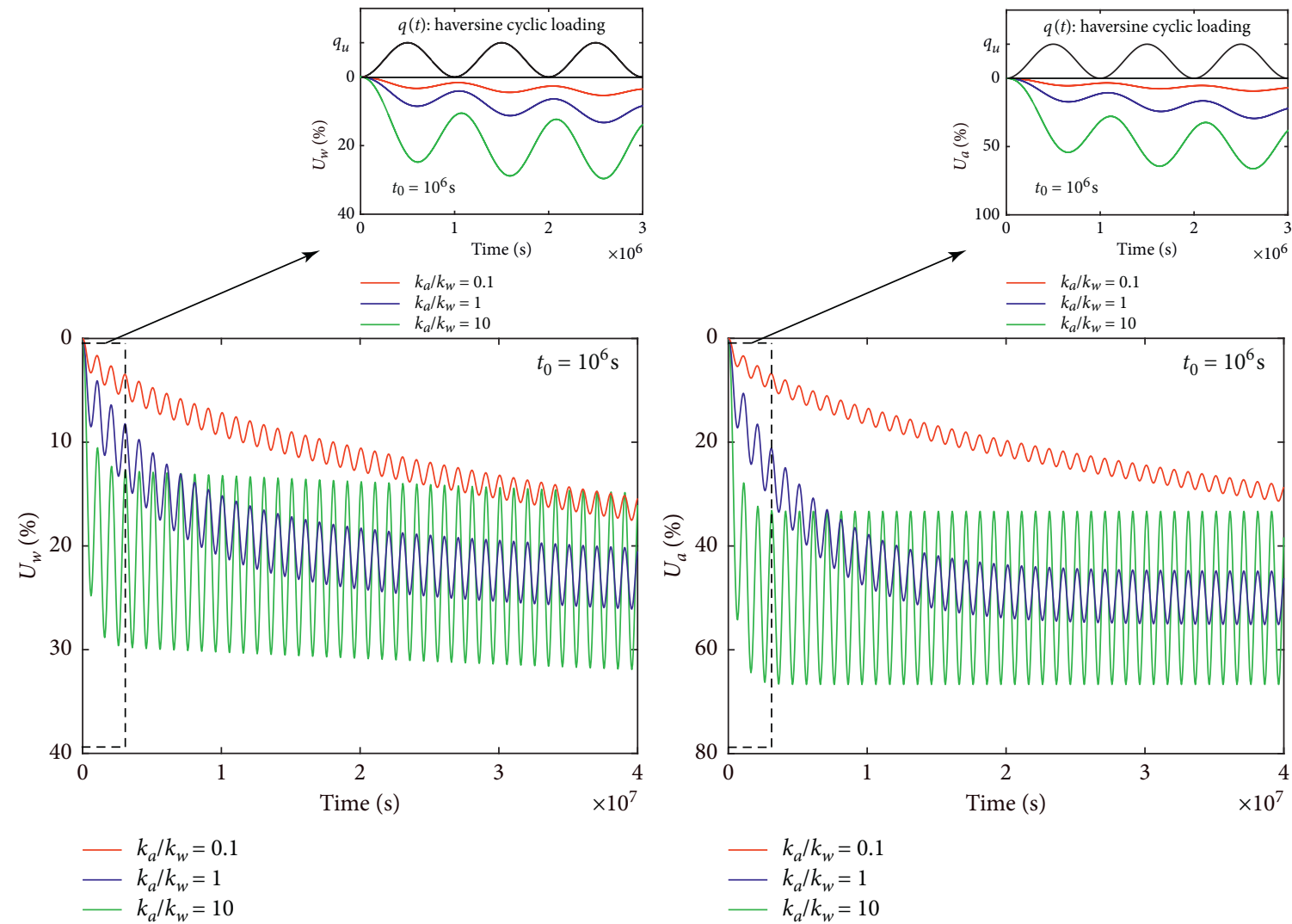

(b)

Figure 8: The effects of $k_{a} / k_{w}$ on consolidation of unsaturated soils under triangular cyclic loading (a) and haversine cyclic loading (b). 

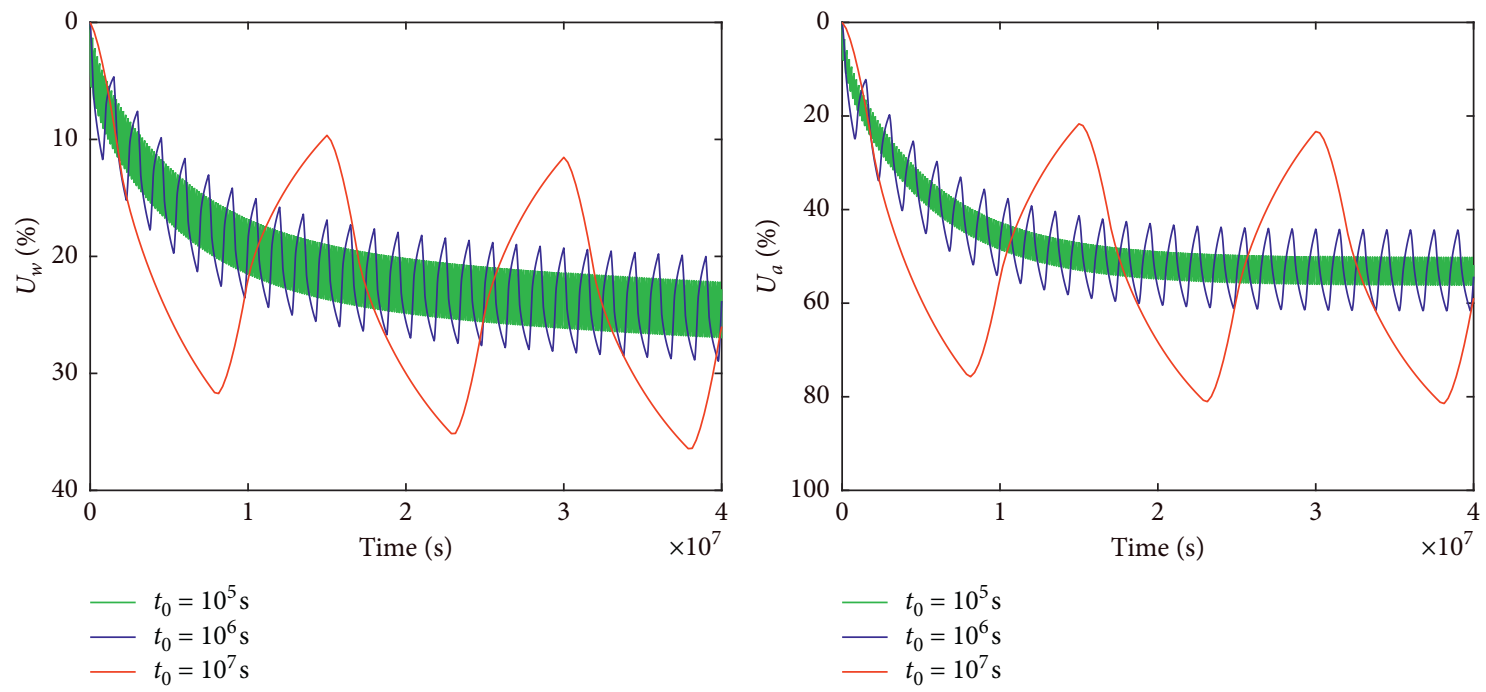

(a)
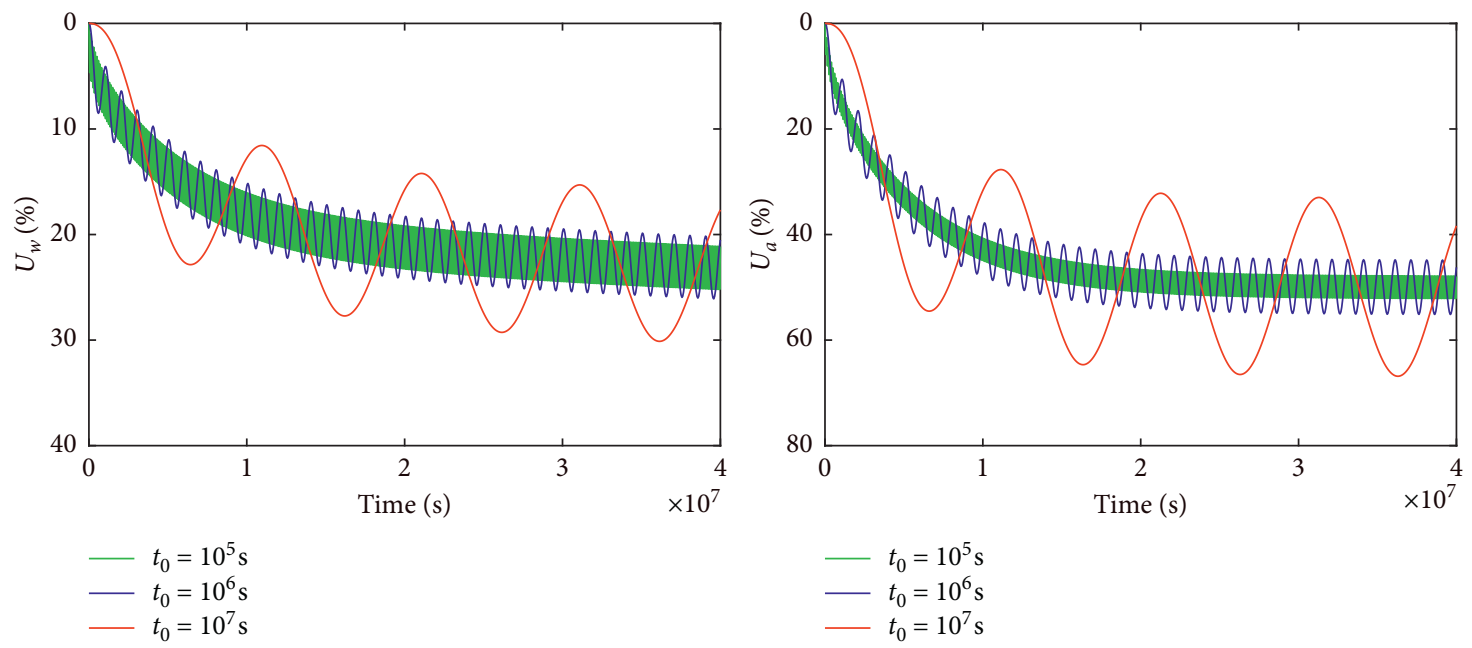

(b)

Figure 9: The effects of $t_{0}$ on consolidation of unsaturated soils under trapezoidal cyclic loading (a) and haversine cyclic loading (b).

phases with time at different values of $k_{a} / k_{w}$ under various cyclic loadings. It can be found that the average degrees of consolidation $U_{w}$ and $U_{a}$ increase but fluctuate with the increase in $k_{a} / k_{w}$, indicating that the dissipation rate of excess pore pressures increase with the fluctuation when $k_{a} / k_{w}$ increases. Moreover, it can be noticed that the higher values of $k_{a} / k_{w}$ lead to the bigger amplitudes of fluctuation in the average degrees of consolidation $U_{w}$ and $U_{a}$.

It can be observed through the locally enlarged diagrams with different cyclic loading forms that there is similar characteristics for the dissipation process of excess pore pressures and the change in applied loading. The variation in the average degrees of consolidation with time shows the oscillation with the same frequency and the similar forms in response to the applied cyclic loadings. It can also be seen that the dissipation process of excess pore pressures does not complete after a long time but rather continues oscillating with a certain amplitude. It is due to repetitive loading and unloading stages of cyclic loadings, which results in squeezing out of pore water and air during the loading stage and then absorbing during the unloading stage.
5.2. Effects of $t_{0}$. Figure 9 demonstrates the variation in average degrees of consolidation for both water and air phases with time under trapezoidal cyclic loading $(\alpha=0.2$ and $\beta=1.5$ ) and haversine cyclic loading with different loading parameters $t_{0}$ for $k_{a} / k_{w}=1$. It can be seen that a smaller value of the loading parameter $t_{0}$ induces a smaller amplitude and more cycles of fluctuation in the dissipation rate of excess pore water and air pressures. In addition, the loading parameter $t_{0}$ has a significant influence on the amplitude and the cycles of fluctuation in the dissipation rate of excess pore pressures but does not affect the mean values of the dissipation rates. The loading parameter $t_{0}$ is the period of loading, and thus, it can be concluded that the longer the period of loading, the bigger the amplitude, and the less the cycles of fluctuation in the dissipation rates.

5.3. Effects of $\alpha$. Figure 10 presents the variation in average degrees of consolidation for both water and air phases with time under different types of cyclic loadings with $\beta=1.5$ and 


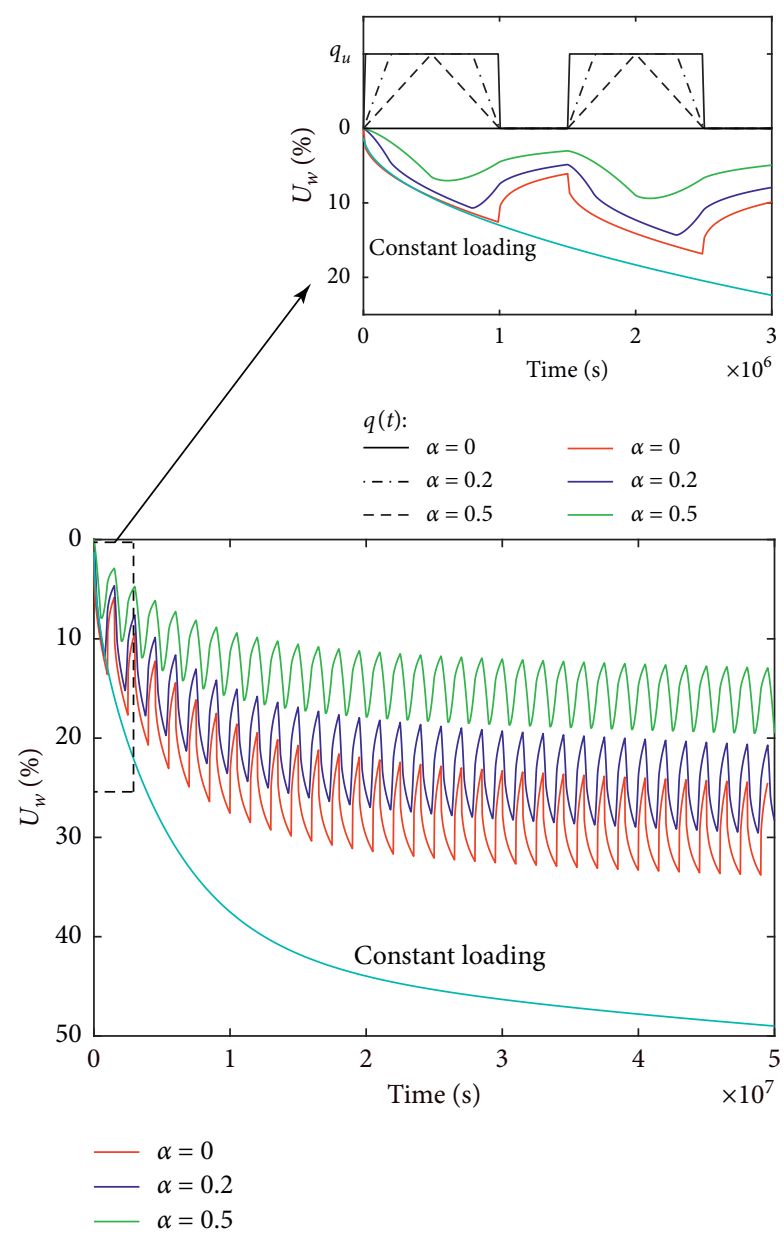

(a)

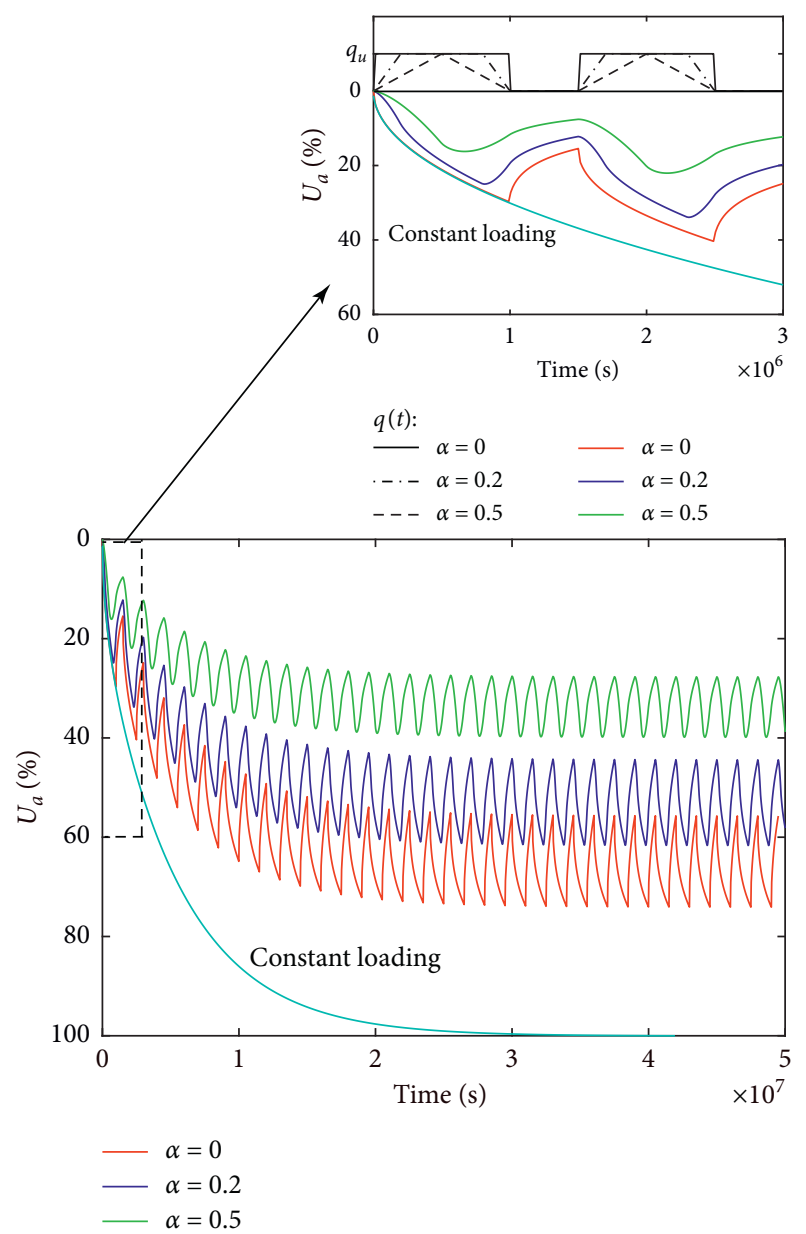

(b)

Figure 10: The effects of $\alpha$ on consolidation of unsaturated soils under various cyclic loadings.

different loading parameters $\alpha$ for $k_{\alpha} / k_{w}=1$. It can be seen that the smaller the loading parameter $\alpha$ is, the more quickly the dissipation of excess pore water and air pressures develops. Since the loading parameter $\alpha$ reflects the rate of loading increment or decrement, it can be found that the higher the rate of loading increment or decrement is, the faster the dissipation rates of excess pore pressures are. Moreover, the dissipation rates of excess pore pressures under rectangular cyclic loading are the biggest and the dissipation rates under triangular cyclic loading are the smallest. For the comparison with the results for static loading, the variation in average degrees of consolidation under constant loading is also shown in Figure 10. It can be observed that the average degrees of consolidation under cyclic loadings increase but fluctuate with a certain amplitude, whereas the average degrees of consolidation under constant loading increase monotonically with time. This phenomenon implies that consolidation of unsaturated soil under cyclic loadings does not complete after a long time, but rather continues oscillating with a certain amplitude, generating continuous volume change of the soil. Thus, neglecting the effect of cyclic loadings may result in overestimated settlement and cannot consider the continuous volume change.
5.4. Effects of $\beta$. Figure 11 depicts the variation in average degrees of consolidation for both water and air phases with time under different cyclic loadings with different loading parameters $\beta$ for $k_{a} / k_{w}=1$. It can be found that the dissipation rates of excess pore water and air pressures increase with the decrease in the value of loading parameter $\beta$. Furthermore, a smaller value of the loading parameter $\beta$ results in more cycles and a smaller amplitude of fluctuation in the dissipation rates. The loading parameter $\beta$ is related to the rest period of loading. Thus, it is quite obvious that a longer rest period of loading induces the decrease in the dissipation rates, less cycles, and a bigger amplitude of fluctuation in the dissipation rates of excess pore pressures. As a result of that the dissipation rates of excess pore water and air pressures under the cyclic loading without rest period $(\beta=1)$ are the biggest for each case. Specifically, rectangular cyclic loading without rest period reduces into constant loading, and the dissipation rates of excess pore water and air pressures are the highest and increase monotonically with time in that case, as shown in Figure 11(b).

It should be noted that the solutions presented in this paper do not consider nonlinear characteristics of soil 

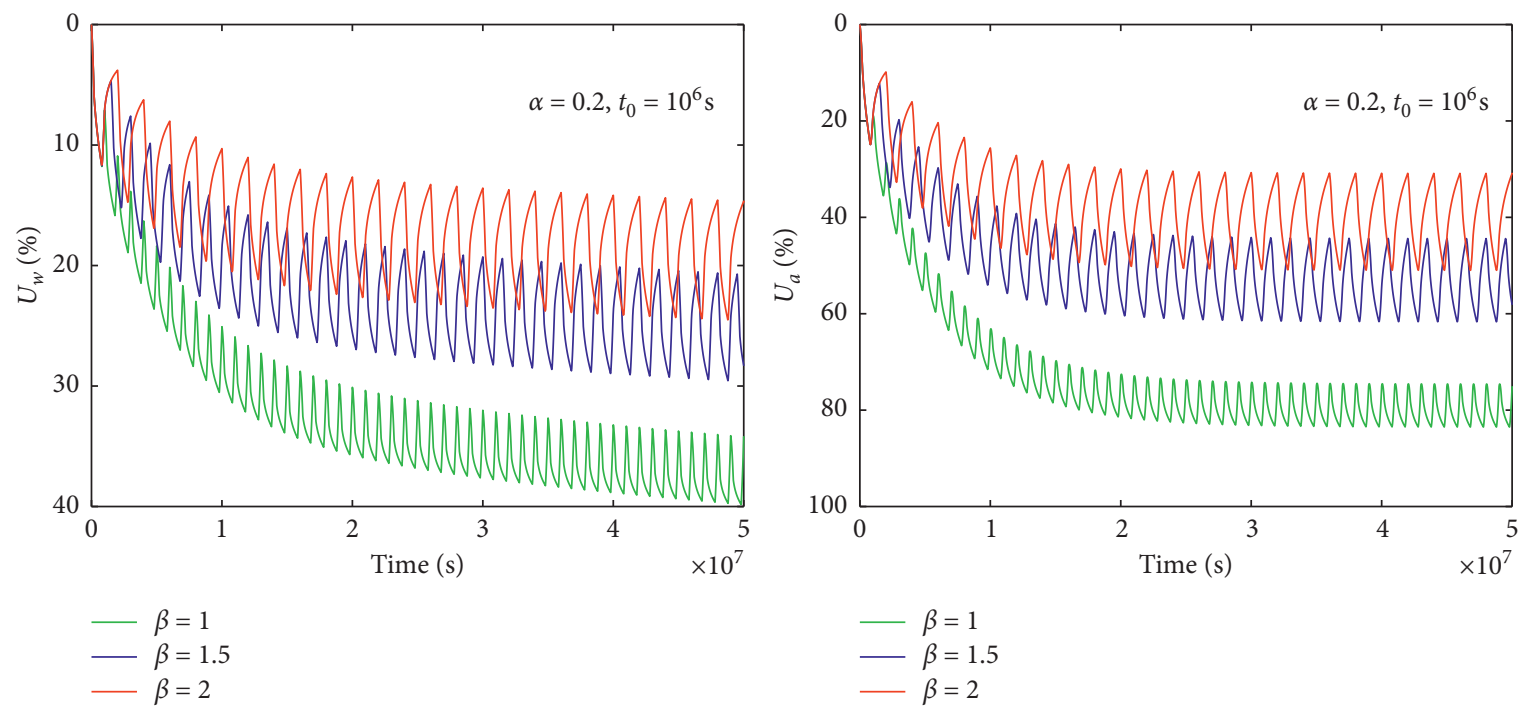

(a)
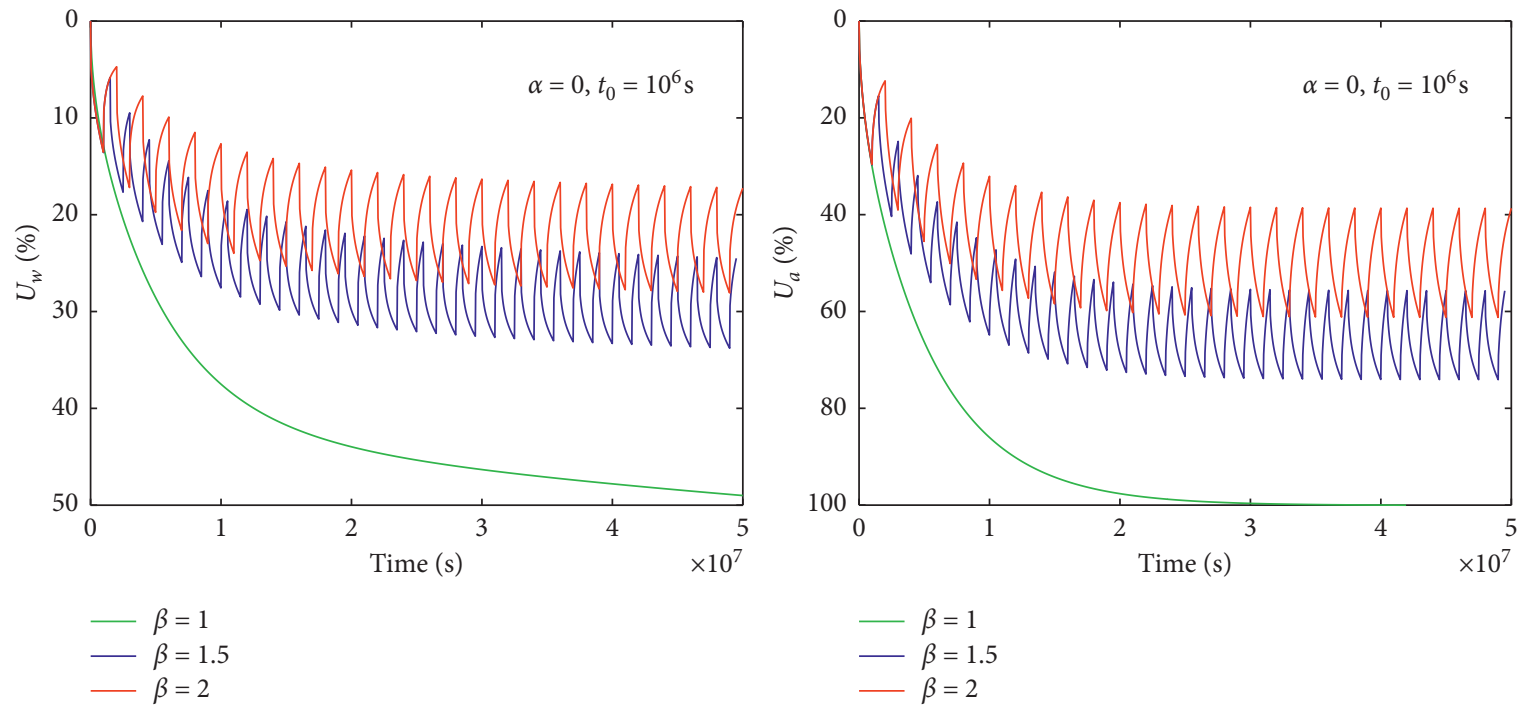

(b)
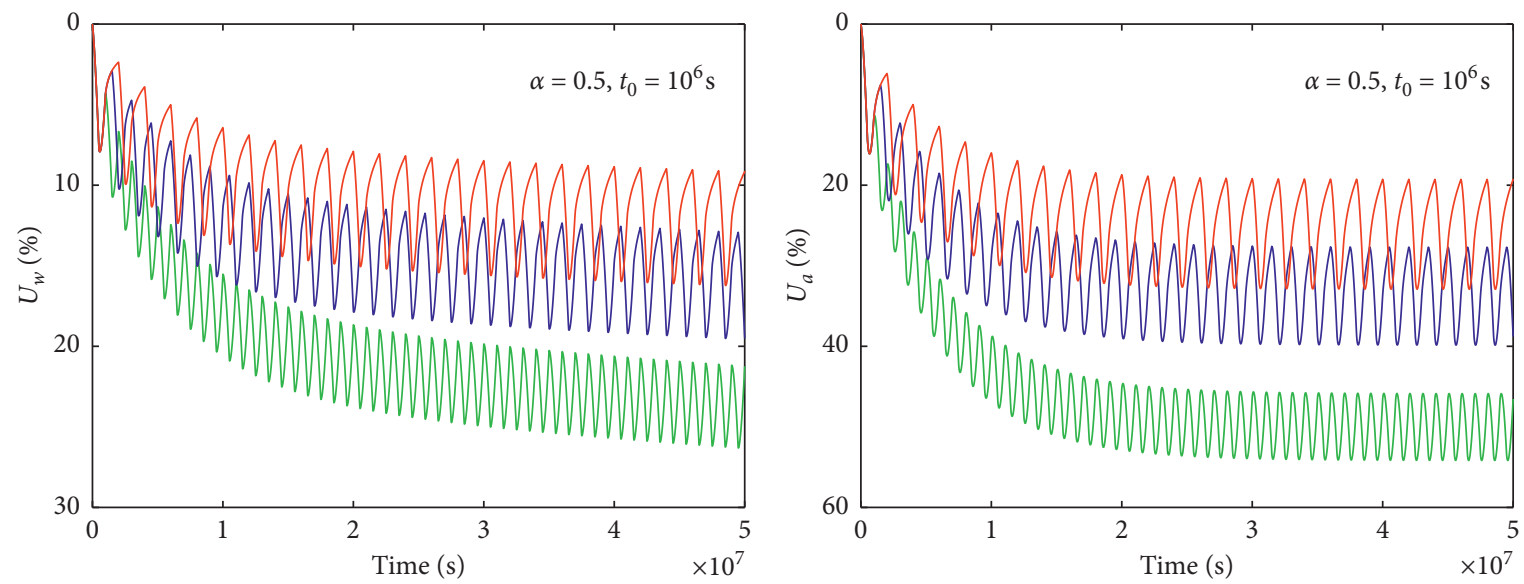

$$
\begin{aligned}
-\beta & =1 \\
-\beta & =1.5
\end{aligned}
$$$$
\begin{aligned}
-\beta & =1 \\
-\beta & =1.5 \\
\beta & =2
\end{aligned}
$$

(c)

Figure 11: The effects of $\beta$ on consolidation of unsaturated soils under various cyclic loadings: (a) trapezoidal cyclic loading; (b) rectangular cyclic loading; (c) triangular cyclic loading. 
properties such as the coefficients of permeability and volume change for both air and water phases under timedependent loading. Even though they are limited for a linear elastic stress-strain model of unsaturated soil based on Fredlund and Hasan's one-dimensional consolidation theory, the proposed solutions are more general ones for one-dimensional consolidation of soils from unsaturated to saturated state under time-dependent loading.

\section{Conclusion}

In this paper, analytical solutions are derived for one-dimensional consolidation of unsaturated soils subjected to various cyclic loadings. It shows through the degeneration into the existing solutions for both unsaturated and saturated soils that the proposed solutions are reliable and more general for one-dimensional consolidation of soils from unsaturated to saturated states under time-dependent loading. The effects of different parameters on one-dimensional consolidation of unsaturated soils under various cyclic loadings are investigated. The main conclusions can be drawn as follows:

(1) The coefficients ratio of permeability for air phase and water phase, $k_{a} / k_{w}$ has sufficient effects on consolidation of the unsaturated soil layer under cyclic loadings. The dissipation rates of excess pore water and air pressures increase with the fluctuation when $k_{a} / k_{w}$ increases. Moreover, the higher values of $k_{a} / k_{w}$ lead to the bigger amplitudes of fluctuation in the dissipation rates.

(2) Under cyclic loadings, the dissipation process of excess pore pressures does not complete after a long time, but rather continues oscillating with a certain amplitude, generating continuous volume change in the soil. Thus, neglecting the effect of cyclic loadings may result in overestimated settlement and cannot consider the continuous volume change.

(3) The cyclic loading parameters such as the period of loading $\left(t_{0}\right)$, the rate of loading increment or decrement $(\alpha)$, and the rest period of loading $(\beta)$ have considerable impacts on consolidation of unsaturated soil. The longer the period of loading, the bigger the amplitude, and the less the cycles of fluctuation in the dissipation rates of excess pore water and air pressures. The higher the rate of loading increment or decrement is, the faster the dissipation rates of excess pore pressures are. A longer rest period of loading induces the decrease in the dissipation rates, less cycles, and a bigger amplitude of fluctuation in the dissipation rates of excess pore pressures.

\section{Appendix}

The average degrees of consolidation for air and water phases under time-dependent loading are defined as follows:

$$
\begin{aligned}
U_{a} & =\left(\bar{q}-\frac{1}{A_{\sigma}} \int_{0}^{1} \bar{u}_{a} \mathrm{~d} \bar{z}\right) \times 100(\%), \\
U_{w} & =\left(\bar{q}-\frac{1}{W_{\sigma}} \int_{0}^{1} \bar{u}_{w} \mathrm{~d} \bar{z}\right) \times 100(\%) .
\end{aligned}
$$

Equations (A.1) and (A.2) can be expressed in terms of $\phi_{i}$ based on equations (26) and (27) as follows:

$$
\begin{aligned}
& U_{a}=\left(\bar{q}-\frac{\alpha_{21} \int_{0}^{1} \phi_{2} \mathrm{~d} \bar{z}-\int_{0}^{1} \phi_{1} \mathrm{~d} \bar{z}}{\left(\alpha_{12} \alpha_{21}-1\right) A_{\sigma}}\right) \times 100(\%), \\
& U_{w}=\left(\bar{q}-\frac{\alpha_{12} \int_{0}^{1} \phi_{1} \mathrm{~d} \bar{z}-\int_{0}^{1} \phi_{2} \mathrm{~d} \bar{z}}{\left(\alpha_{12} \alpha_{21}-1\right) W_{\sigma}}\right) \times 100(\%) .
\end{aligned}
$$

Transforming (A.3) and (A.4) mathematically,

$$
\begin{aligned}
& U_{a}=\frac{\alpha_{21}\left(\eta_{2} \bar{q}-\int_{0}^{1} \phi_{2} \mathrm{~d} \bar{z}\right)-\left(\eta_{1} \bar{q}-\int_{0}^{1} \phi_{1} \mathrm{~d} \bar{z}\right)}{\left(\alpha_{12} \alpha_{21}-1\right) A_{\sigma}} \times 100(\%), \\
& U_{w}=\frac{\alpha_{12}\left(\eta_{1} \bar{q}-\int_{0}^{1} \phi_{1} \mathrm{~d} \bar{z}\right)-\left(\eta_{2} \bar{q}-\int_{0}^{1} \phi_{2} \mathrm{~d} \bar{z}\right)}{\left(\alpha_{12} \alpha_{21}-1\right) A_{\sigma}} \times 100(\%) .
\end{aligned}
$$

Therefore, (A.5) and (A.6) can be rewritten in the following form:

$$
\begin{gathered}
U_{a}=\frac{\alpha_{21} U_{2}-U_{1}}{\left(\alpha_{12} \alpha_{21}-1\right) A_{\sigma}} \times 100(\%), \\
U_{w}=\frac{\alpha_{12} U_{1}-U_{2}}{\left(\alpha_{12} \alpha_{21}-1\right) A_{\sigma}} \times 100(\%),
\end{gathered}
$$

where $U_{1}$ and $U_{2}$ are the degrees of consolidation with respect to $\phi_{1}$ and $\phi_{2}$ defined as follows:

$$
\begin{aligned}
& U_{1}=\eta_{1} \bar{q}-\int_{0}^{1} \phi_{1} \mathrm{~d} \bar{z}, \\
& U_{2}=\eta_{2} \bar{q}-\int_{0}^{1} \phi_{2} \mathrm{~d} \bar{z} .
\end{aligned}
$$

\section{Data Availability}

The data used to support the findings of this study are included within the article.

\section{Conflicts of Interest}

The authors declare that there are no conflicts of interest regarding the publication of this paper. 


\section{Acknowledgments}

This work was supported by Kim II Sung University in DPR of Korea.

\section{References}

[1] N. E. Wilson and M. M. Elgohary, "Consolidation of soils under cyclic loading," Canadian Geotechnical Journal, vol. 11, no. 3, pp. 420-423, 1974.

[2] M. Favaretti and M. Soranzo, "A simplified consolidation theory in cyclic loading conditions," in Proceedings of the International Symposium on Compression and Consolidation of Clayey Soils, pp. 405-409, A. A. Balkema, Rotterdam, Netherlands, 1995.

[3] E. Conte and A. Troncone, "One-dimensional consolidation under general time-dependent loading," Canadian Geotechnical Journal, vol. 43, no. 11, pp. 1107-1116, 2006.

[4] S. S. Razouki and T. Schanz, "One-dimensional consolidation under haversine repeated loading with rest period," Acta Geotechnica, vol. 6, no. 1, pp. 13-20, 2011.

[5] S. S. Razouki, P. Bonnier, M. Datcheva, and T. Schanz, "Analytical solution for 1D consolidation under haversine cyclic loading," International Journal for Numerical and Analytical Methods in Geomechanics, vol. 37, no. 14, pp. 2367-2372, 2013.

[6] P. Kim, Y.-G. Kim, C.-H. Paek, and J. Ma, "Lattice Boltzmann method for consolidation analysis of saturated clay," Journal of Ocean Engineering and Science, vol. 4, no. 3, pp. 193-202, 2019.

[7] M. M. Baligh and J. N. Levadoux, "Consolidation theory for cyclic loading," Journal of the Geotechnical Engineering Division, ASCE, vol. 104, no. 4, pp. 415-431, 1978.

[8] K.-h. Xie, T. Qi, and Y.-q. Dong, "Nonlinear analytical solution for one-dimensional consolidation of soft soil under cyclic loading," Journal of Zhejiang University-Science A, vol. 7, no. 8, pp. 1358-1364, 2006.

[9] X. Geng, C. Xu, and Y. Cai, "Non-linear consolidation analysis of soil with variable compressibility and permeability under cyclic loadings," International Journal for Numerical and Analytical Methods in Geomechanics, vol. 30, no. 8, pp. 803-821, 2006.

[10] Y.-Q. Cai, X.-Y. Geng, and C.-J. Xu, "Solution of one-dimensional finite-strain consolidation of soil with variable compressibility under cyclic loadings," Computers and Geotechnics, vol. 34, no. 1, pp. 31-40, 2007.

[11] E. Conte and A. Troncone, "Nonlinear consolidation of thin layers subjected to time-dependent loading," Canadian Geotechnical Journal, vol. 44, no. 6, pp. 717-725, 2007.

[12] M. M. Toufigh and A. Ouria, "Consolidation of inelastic clays under rectangular cyclic loading," Soil Dynamics and Earthquake Engineering, vol. 29, no. 2, pp. 356-363, 2009.

[13] D. Cheng, W. Wang, X. Chen, and Z. Zhang, "Finite analytic method for one-dimensional nonlinear consolidation under time-dependent loading," Shock and Vibration, vol. 2017, Article ID 4071268, 12 pages, 2017.

[14] J. Hu, X. Bian, and Y. Chen, "Nonlinear consolidation of multilayer soil under cyclic loadings," European Journal of Environmental and Civil Engineering, pp. 1-23, 2019.

[15] P. Kim, Y. G. Kim, H. B. Myong, C. H. Paek, and J. Ma, "Numerical analysis for nonlinear consolidation of saturated soil using lattice Boltzmann method," International Research Journal of Engineering and Technology, vol. 6, no. 4, pp. 3611-3618, 2019, https://www.irjet.net/archives/V6/i4/ IRJET-V6I4770.pdf.

[16] P. Kim, K. S. Ri, Y. G. Kim, K. N. Sin, H. B. Myong, and C. H. Paek, "Nonlinear consolidation analysis of a saturated clay layer with variable compressibility and permeability under various cyclic loadings," International Journal of Geomechanics, Article ID 0001730, 2020.

[17] E. H. Davis and G. P. Raymond, "A non-linear theory of consolidation," Géotechnique, vol. 15, no. 2, pp. 161-173, 1965.

[18] G. E. Blight, Strength and consolidation characteristics of compacted soils, Ph.D. thesis, University of London, London, England, 1961.

[19] L. Barden, "Consolidation of compacted and unsaturated clays," Géotechnique, vol. 15, no. 3, pp. 267-286, 1965.

[20] D. G. Fredlund and J. U. Hasan, "One-dimensional consolidation theory: unsaturated soils," Canadian Geotechnical Journal, vol. 16, no. 3, pp. 521-531, 1979.

[21] B. A. Schrefler and Z. Xiaoyong, "A fully coupled model for water flow and airflow in deformable porous media," Water Resources Research, vol. 29, no. 1, pp. 155-167, 1993.

[22] E. Conte, "Consolidation analysis for unsaturated soils," Canadian Geotechnical Journal, vol. 41, no. 4, pp. 599-612, 2004.

[23] E. Conte, "Plane strain and axially symmetric consolidation in unsaturated soils," International Journal of Geomechanics, vol. 6, no. 2, pp. 131-135, 2006.

[24] D. G. Fredlund and H. Rahardjo, Soil Mechanics for Unsaturated Soils, Wiley, New York, NY, USA, 1993.

[25] D. G. Fredlund, H. Rahardjo, and M. D. Fredlund, Unsaturated Soil Mechanics in Engineering Practice, Wiley, Hoboken, NJ, USA, 2012.

[26] A.-f. Qin, G.-j. Chen, Y.-w. Tan, and D.-a. Sun, "Analytical solution to one-dimensional consolidation in unsaturated soils," Applied Mathematics and Mechanics, vol. 29, no. 10, pp. 1329-1340, 2008.

[27] A. Qin, D. A. Sun, and Y. Tan, "Analytical solution to onedimensional consolidation in unsaturated soils under loading varying exponentially with time," Computers and Geotechnics, vol. 37, no. 1-2, pp. 233-238, 2010.

[28] Z. Shan, D. Ling, and H. Ding, "Exact solutions for one-dimensional consolidation of single-layer unsaturated soil," International Journal for Numerical and Analytical Methods in Geomechanics, vol. 36, no. 6, pp. 708-722, 2012.

[29] W.-H. Zhou, L.-S. Zhao, and X.-B. Li, "A simple analytical solution to one-dimensional consolidation for unsaturated soils," International Journal for Numerical and Analytical Methods in Geomechanics, vol. 38, no. 8, pp. 794-810, 2014.

[30] J. Feng, X.-y. Wu, B.-l. Zhu, and Q.-x. Yang, "Analytical solution to one-dimensional consolidation in unsaturated soils under sinusoidal cyclic loading," Journal of Central South University, vol. 22, no. 2, pp. 646-653, 2015.

[31] L. Ho and B. Fatahi, "One-dimensional consolidation analysis of unsaturated soils subjected to time-dependent loading," International Journal of Geomechanics, 2015.

[32] L. Wang, D. A. Sun, A. F. Qin, and Y. F. Xu, "Semi-analytical solution to one-dimensional consolidation for unsaturated soils with semi-permeable drainage boundary under timedependent loading," International Journal for Numerical and Analytical Methods in Geomechanics, vol. 41, no. 16, pp. 1636-1655, 2017.

[33] W.-H. Zhou and L.-S. Zhao, "One-dimensional consolidation of unsaturated soil subjected to time-dependent loading with various initial and boundary conditions," International Journal of Geomechanics, vol. 14, no. 2, pp. 291-301, 2014. 
[34] A. Qin, D. A. Sun, L. Yang, and Y. Weng, "A semi-analytical solution to consolidation of unsaturated soils with the free drainage well," Computers and Geotechnics, vol. 37, no. 7-8, pp. $867-875,2010$.

[35] L. Ho, B. Fatahi, and H. Khabbaz, "Analytical solution to axisymmetric consolidation in unsaturated soils with linearly depth-dependent initial conditions," Computers and Geotechnics, vol. 74, pp. 102-121, 2016.

[36] L. Ho and B. Fatahi, "Axisymmetric consolidation in unsaturated soil deposit subjected to time-dependent loadings," International Journal of Geomechanics, vol. 17, no. 2, Article ID 04016046, 2016.

[37] L. Ho and B. Fatahi, "Analytical solution to axisymmetric consolidation of unsaturated soil stratum under equal strain condition incorporating smear effects," International Journal for Numerical and Analytical Methods in Geomechanics, vol. 42, no. 15, pp. 1890-1913, 2018.

[38] W. H. Zhou, L. S. Zhao, T. M. H. Lok, G. X. Mei, and X. B. Li, "Analytical solutions to the axisymmetric consolidation of unsaturated soils," Journal of Engineering Mechanics, ASCE, vol. 144, no. 1, Article ID 04017152, 2018.

[39] L. Ho, B. Fatahi, and H. Khabbaz, "A closed form analytical solution for two-dimensional plane strain consolidation of unsaturated soil stratum," International Journal for Numerical and Analytical Methods in Geomechanics, vol. 39, no. 15, pp. 1665-1692, 2015.

[40] L. Ho and B. Fatahi, "Analytical solution for the two-dimensional plane strain consolidation of an unsaturated soil stratum subjected to time-dependent loading," Computers and Geotechnics, vol. 67, pp. 1-16, 2015.

[41] L. Wang, Y. Xu, X. Xia, and D. A. Sun, "Semi-analytical solutions to two-dimensional plane strain consolidation for unsaturated soil," Computers and Geotechnics, vol. 101, pp. 100-113, 2018.

[42] L. Wang, Y. Xu, X. Xia, Y. He, and T. Li, "Semi-analytical solutions to two-dimensional plane strain consolidation for unsaturated soils under time-dependent loading," Computers and Geotechnics, vol. 109, pp. 144-165, 2019.

[43] L. Wang, Y. Xu, X. Xia, Y. He, and T. Y. Li, "Semi-analytical solutions of two-dimensional plane strain consolidation in unsaturated soils subjected to the lateral semipermeable drainage boundary," International Journal for Numerical and Analytical Methods in Geomechanics, vol. 43, no. 17, pp. 2628-2651, 2019.

[44] W.-C. Lo, G. Sposito, J.-W. Lee, and H. Chu, "One-dimensional consolidation in unsaturated soils under cyclic loading," Advances in Water Resources, vol. 91, pp. 122-137, 2016. 